\title{
Is There Evidence of Changes in Tropical Atlantic Variability Modes under AMO Phases in the Observational Record?
}

\author{
MARTA MARTÍN-REY \\ Departamento de Física de la Tierra, Astronomía y Astrofísica I (Geofísica y Meteorología), \\ Facultad de Ciencias Físicas, Universidad Complutense de Madrid, Madrid, Spain, \\ and LOCEAN-IPSL, UPMC, Sorbonne Universités, Paris, France \\ IRENE POLO \\ Departamento de Física de la Tierra, Astronomía y Astrofísica I (Geofísica y Meteorología), Facultad de \\ Ciencias Físicas, Universidad Complutense de Madrid, Madrid, Spain, and Department of \\ Meteorology, University of Reading, Reading, United Kingdom \\ BELÉN RodRÍGUEZ-FonseCA AND TERESA LOSADA \\ Departamento de Física de la Tierra, Astronomía y Astrofísica I (Geofísica y Meteorología), Facultad de \\ Ciencias Físicas, Universidad Complutense de Madrid, Madrid, Spain \\ AlbAn LAZAR \\ LOCEAN-IPSL, UPMC, Sorbonne Universités, Paris, France
}

(Manuscript received 17 June 2016, in final form 9 June 2017)

\begin{abstract}
The Atlantic multidecadal oscillation (AMO) is the leading mode of Atlantic sea surface temperature (SST) variability at multidecadal time scales. Previous studies have shown that the AMO could modulate El Niño-Southern Oscillation (ENSO) variance. However, the role played by the AMO in the tropical Atlantic variability (TAV) is still uncertain. Here, it is demonstrated that during negative AMO phases, associated with a shallower thermocline, the eastern equatorial Atlantic SST variability is enhanced by more than $150 \%$ in boreal summer. Consequently, the interannual TAV modes are modified. During negative AMO, the Atlantic Niño displays larger amplitude and a westward extension and it is preceded by a simultaneous weakening of both subtropical highs in winter and spring. In contrast, a meridional seesaw SLP pattern evolving into a zonal gradient leads the Atlantic Niño during positive AMO. The north tropical Atlantic (NTA) mode is related to a Scandinavian blocking pattern during winter and spring in negative AMO, while under positive AMO it is part of the SST tripole associated with the North Atlantic Oscillation. Interestingly, the emergence of an overlooked variability mode, here called the horseshoe (HS) pattern on account of its shape, is favored during negative AMO. This anomalous warm (cool) HS surrounding an eastern equatorial cooling (warming) is remotely forced by an ENSO phenomenon. During negative AMO, the tropicalextratropical teleconnections are enhanced and the Walker circulation is altered. This, together with the increased equatorial SST variability, could promote the ENSO impacts on TAV. The results herein give a step forward in the better understanding of TAV, which is essential to improving its modeling, impacts, and predictability.
\end{abstract}

Supplemental information related to this paper is available at the Journals Online website: https://doi.org/10.1175/JCLID-16-0459.s1.

Corresponding author: Marta Martín del Rey, mmartindelrey@ fis.ucm.es

\section{Introduction}

The Atlantic multidecadal oscillation (AMO) is the leading mode of internal multidecadal SST variability in the Atlantic Ocean (Kerr 2000; Knight et al. 2006). The positive phase of the AMO is characterized by an anomalous warming in North Atlantic and cooler SST 
anomalies south of the equator. Previous studies have reported that the AMO could modulate northeastern Brazilian and Sahelian rainfall (Knight et al. 2006), European summer climate (Sutton and Hodson 2003; Sutton and Dong 2012), and hurricane activity in the Atlantic Ocean (Goldenberg 2001; Vimont and Kossin 2007; Zhang and Delworth 2007). Furthermore, negative AMO phases have been allied with changes in the tropical Pacific mean state, altering the El NiñoSouthern Oscillation (ENSO) annual cycle and increasing its variance (Dong et al. 2006; Dong and Sutton 2007; Levine et al. 2017). Nevertheless, the influence of the AMO on the tropical Atlantic variability (TAV) remains unclear. Model studies have stated that a weakening of the Atlantic meridional overturning circulation (AMOC) resembles a surface negative AMO-like response. Consequently, the thermocline is deepened and the SST variability is reduced in the eastern equatorial Atlantic during boreal summer and fall (Haarsma et al. 2008; Polo et al. 2013). Nevertheless, other authors have shown stronger zonal SST gradients in the equatorial Atlantic and thus enhanced summer SST variability as a response of a weakened AMOC (Svendsen et al. 2014). In contrast, Tokinaga and Xie (2011) have not found significant correlations between TAV and the AMO, attributing the observed negative trend in the cold tongue variance to the global warming effect.

At interannual time scales, TAV is governed by two air-sea coupled modes: an interhemispheric pattern, denoted as the meridional mode (Nobre and Shukla 1996; Enfield and Mayer 1997; Ruiz-Barradas et al. 2000), and a zonal mode, named the Atlantic Niño (Merle 1980; Zebiak 1993). The meridional mode peaks in boreal spring and is characterized by an interhemispheric SST gradient. Accordingly, the ITCZ suffers a meridional displacement to the warmer hemisphere and originates cross-equatorial surface winds (Xie and Philander 1994; Chiang et al. 2002). The meridional mode development is attributed to thermodynamic airsea interactions (Carton et al. 1996; Ruiz-Barradas et al. 2000) related to the wind-evaporation-SST (WES) feedback (Chang et al. 1997; Amaya et al. 2017). Under warmer north tropical Atlantic (NTA) conditions, the ITCZ migrates to the north, weakening the northeasterly winds and intensifying the trades south of the equator (Xie and Philander 1994; Chiang and Vimont 2004). The wind-induced latent heat fluxes reinforce the initial dipolar SST configuration, establishing the positive feedback (Carton et al. 1996; Wagner 1996; Chang et al. 1997; Amaya et al. 2017). The occurrence of a positive meridional mode is accompanied by precipitation anomalies over Nordeste Brazil and eastern Amazonia (Moura and
Shukla 1981; Nobre and Shukla 1996; Chiang et al. 2002), as well as enhanced hurricane activity (Xie et al. 2005; Kossin and Vimont 2007). Recently, several authors have posed that boreal spring NTA SST anomalies are able to trigger an ENSO phenomenon during next winter (Ham et al. 2013). Furthermore, this link could take part in a discharge-recharge Atlantic-Pacific oscillator, favored by the positive phase of AMO and the global warming trend (Wang et al. 2017).

The Atlantic Niño has been traditionally associated with a relaxation of the climatological trade winds and warm SST anomalies in the equatorial Atlantic during boreal summer (Zebiak 1993; Carton and Huang 1994; Carton et al. 1996; Keenlyside and Latif 2007). The anomalous westerlies could be part of a large-scale weakening of the St. Helena high and could excite Rossby and Kelvin oceanic waves, contributing to develop the Atlantic Niño pattern (Polo et al. 2008; Lübbecke et al. 2010; Lübbecke and McPhaden 2012; Lübbecke et al. 2014). Despite the dynamical nature of the Atlantic Niño (Bjerknes 1969; Keenlyside and Latif 2007), recent studies have underlined the importance of other processes on its growth. In this sense, meridional advection of NTA subsurface temperature anomalies to the equator (Richter et al. 2013) and surface heat fluxes (Nnamchi et al. 2015, 2016) could significantly contribute to generate the Atlantic Niño.

The Atlantic Niño teleconnections have been modified and become stronger after the 1970s (Kucharski et al. 2008; Polo et al. 2008; Rodríguez-Fonseca et al. 2009; Losada et al. 2012a,b; Martín-Rey et al. 2014). In particular, a summer Atlantic Niño (Niña) is able to trigger the next winter Pacific La Niña (El Niño) through an air-sea coupled mechanism (Keenlyside and Latif 2007; Rodríguez-Fonseca et al. 2009; Losada et al. 2010; Ding et al. 2012; Polo et al. 2015a; Losada and Rodríguez-Fonseca 2016). This interbasin connection emerges as a coupled variability mode at multidecadal time scales, coinciding with negative phases of the AMO (Martín-Rey et al. 2014). The nonstationary impact of the north tropical and equatorial Atlantic on ENSO brings to light the possible modulator role of the natural low-frequency variability in the interannual one (Martín-Rey et al. 2014, 2015; Wang et al. 2017).

External forcings, as the North Atlantic Oscillation (NAO; Hurrell et al. 2001) and ENSO can exert a strong influence on TAV (Enfield and Mayer 1997; Saravanan and Chang 2000; Czaja et al. 2002; Handoh et al. 2006a,b). The NAO is highly linked to fluctuations in the Azores high, modifying the surface winds. As a consequence, the latent heat flux changes, contributing to generate SST anomalies in the NTA (Czaja et al. 2002; 
Rodríguez-Fonseca and de Castro 2002; Pan 2005). On the other hand, the ENSO phenomenon is able to excite extratropical atmospheric wave trains emanating from the tropical Pacific (Handoh et al. 2006a,b). These atmospheric waves reach the Atlantic basin and alter the subtropical high pressure systems and, in turn, the trade winds (Nobre and Shukla 1996; Enfield and Mayer 1997; Chiang et al. 2002; Handoh et al. 2006a,b). Likewise, ENSO can also modify the Walker circulation, perturbing the Atlantic ITCZ. The anomalous equatorial winds could then trigger oceanic Kelvin waves, promoting the Atlantic Niño development (Latif and Grötzner 2000; Münnich and Neelin 2005).

NAO and ENSO impacts on the Atlantic climate have experienced a multidecadal modulation along the observational record. A strengthening of the atmospheric waveguides (Mariotti et al. 2002; López-Parages and Rodríguez-Fonseca 2012) and a strong link between the Pacific and Atlantic ITCZ (Chiang et al. 2000) have been reported. This could cause more effective ENSO teleconnections during negative AMO phases. Additionally, interdecadal NAO fluctuations (Pozo-Vázquez et al. 2001) have been associated with decadal Atlantic ITCZ variations (Rajagopalan et al. 1998) and AMOlike SST conditions ( $\mathrm{Li}$ et al. 2013).

In this context, the present study sheds light about the changes suffered by the observed interannual tropical Atlantic SST variability in different AMO phases. The TAV modes, as well as their local and remote influences, are investigated along the observational record. The results are conciliated with the existing knowledge. The paper is structured as follows. Section 2 shows the data and methodology. The main results are presented in section 3. Section 3a illustrates the changes in the atmospheric and oceanic background state related to the AMO phases. The three main TAV modes are described in section 3b. A detailed analysis of each mode and its forcings is found in sections $3 \mathrm{c}$ to $3 \mathrm{e}$. Finally, the conclusions and discussion are presented in section 4 .

\section{Data and methodology}

Observations and atmospheric reanalysis have been used. SSTs have been taken from the HadISST dataset (Rayner et al. 2003) for the period 1870 to 2014. Sea level pressure (SLP) and surface wind come from the ERA-20C reanalysis (Poli et al. 2013) for the period 1900 to 2010 . The isotherm of $16^{\circ} \mathrm{C}$, considered as a proxy of the thermocline depth, has been taken from the SODA reanalysis for the period 1871-2002 (Giese and Ray 2011). The precipitation comes from the CRU dataset for the period 1901-2013 (Harris et al. 2014).
Seasonal anomalies have been calculated by subtracting the climatological seasonal cycle of the whole period. To isolate the interannual variability, a high-pass Butterworth filter (Butterworth 1930) has been applied to the anomalies. The cutoff frequency selected $(7 \mathrm{yr})$ is adequate for interannual studies, since it removes the low-frequency signal and the global warming trend. If the cutoff frequency is increased to 10 years, part of the low-frequency variability interacts with the highfrequency one, leading to degenerate multiplets of the TAV modes (not shown).

The calculation of the dominant modes of tropical Atlantic SST variability has been done by applying principal component analysis (PCA). This technique consists of the decomposition of an anomalous spacetime field $Y\left(n_{s}, n_{t}\right)$ into a number of modes that maximize its variance, with $n_{s}$ being the spatial dimension and $n_{t}$ the temporal one. A set of spatial structures [empirical orthogonal functions (EOFs)] and time series [principal components (PCs)] are obtained. The combination of an EOF and the associated PC describes a mode of variability that explains a fraction of the total variance of the original field $Y$ (von Storch and Zwiers 2001). The independence of the EOFs has been assessed using the North criterion (North et al. 1982). Because of the orthogonality constraint, PCA has a tendency to produce unphysical modes. This feature can be partly solved by rotating the spatial EOF patterns (Horel and Wallace 1981; Richman 1986). Here we present the unrotated EOFs. However, the coherence of these spatial structures has been confirmed through the rotation of the SST patterns, using the varimax algorithm (Kaiser 1958). Similar EOF patterns are found, independent of the number of modes retained (not shown), which gives robustness to the results. Moreover, the same modes are obtained when the PCA is applied to different SST datasets (e.g., ERSST and SODA, not shown).

Following the results of Martín-Rey et al. (2014), two subperiods of negative and positive AMO phases have been considered. To create the two samples, we have chosen the longest common period for all datasets: 1900-2008. For the AMO positive period, we have selected years in which the AMO standardized index exceeds a value of +0.5 . In this way, a total of 34 years makes up the AMO positive period: 1928-42, 1951-60, and 1999-2007. Consistently, for the AMO negative period we have chosen years in which AMO index takes values below -0.5 , making a total of 38 years: $1906-09$, 1918-23, and 1968-95.

To compute the AMO index we have followed the methodology described by Mohino et al. (2011) and Villamayor and Mohino (2015). First of all, a global 
warming (GW) index has been calculated as the low-pass filtered (40-yr cutoff) time series of average SST between $45^{\circ} \mathrm{S}$ and $60^{\circ} \mathrm{N}$. The regression of the original anomalous SST onto this GW index generates a regression coefficient that has been multiplied at each grid point by the GW index, constructing a GW space-time field. This space-time GW field has been subtracted to the original SST, giving rise to the residual SST field. The AMO pattern emerges as the leading mode of the a low-pass filtered (13-yr cutoff frequency) residual SST (Villamayor and Mohino 2015). Although the AMO index exhibits slight variations in amplitude and shape, depending on whether a running mean or a Butterworth filter is applied, the resultant AMO periods are similar.

The Atl 3 index, defined as the SST averaged in the region $\left[4^{\circ} \mathrm{N}-4^{\circ} \mathrm{S}, 20^{\circ} \mathrm{W}-0^{\circ} \mathrm{E}\right]$, has been used as an indicator of the equatorial Atlantic variability. Significant results at $95 \%$ confidence level according to a Monte Carlo test, $t$ test, or F test (depending on the calculation) are presented.

\section{Results}

\section{a. Changes in the background state and equatorial Atlantic variability under AMO phases}

Along the twentieth century, the eastern equatorial Atlantic SST has suffered interdecadal changes in both its amplitude (red line, Fig. 1a) and its variability (purple dashed line, Fig. 1a). These decadal fluctuations coincide with transitions between AMO phases (green line, Fig. 1a). The variability in the Atl3 region during summer and fall is enhanced in negative AMO periods, as confirmed by the ratio of Atl3 variances in negative AMO periods with respect to positive ones $(\sim 150 \%$ from June to November; blue dots, Fig. 1b). This enhancement is statistically significant and independent of the subperiod considered for each AMO phase (red dots, Fig. 1b).

Figure 2 shows the differences in climatological fields between negative and positive AMO phases. During negative AMO periods, the upper-level westerly winds are weakened (Fig. 2a) and the Walker circulation is strengthened (Fig. 2b). This could be probably caused by the southward migration of the ITCZ, a feature that can be inferred from the differences in the zonal wind and SLP over the equatorial band (Figs. 2c,d). Intensified zonal winds north of the equator, together with a reduction in STA, are in agreement with a southern displacement of the ITCZ as a response to an interhemispheric SST gradient with cooler SSTs in the North Atlantic (Fig. 2e). Also, during negative AMO the SLP anomalies are stronger over the subtropical North Atlantic (Fig. 2d), resembling a positive NAO-like configuration (Rajagopalan et al. 1998;
Li et al. 2013). These atmospheric conditions could favor more efficient ENSO teleconnections during those decades (Chiang et al. 2000; Wang 2006; López-Parages and Rodríguez-Fonseca 2012). Regarding the oceanic conditions, during negative AMO phases the tropical Atlantic Ocean presents a shallower thermocline in the centraleastern equatorial Atlantic (Fig. 2f). This shift in the thermocline slope could involve more effective Bjerknes feedback (Bjerknes 1969) along the equator, enhancing the eastern SST variability (Fig. 1b).

Under this modified oceanic background state and altered atmospheric teleconnections, changes in the interannual TAV modes are expected. The TAV modes emerging during different AMO phases are described in next section.

\section{b. TAV modes under different AMO phases}

During the entire twentieth century, the summer tropical Atlantic SST interannual variability is driven by three independent modes (Figs. 3a-c). The leading mode resembles an Atlantic Niño pattern, with anomalous warming (cooling) in the tropical Atlantic and maximum anomalies along the equatorial band (Fig. 3a). The second mode (the NTA mode) shows anomalous warm (cold) conditions in north tropical Atlantic region and weak negative (positive) SST anomalies south of the equator; (Fig. 3b). Finally, the third mode (here called the HS pattern) displays a horseshoe-like pattern of SST anomalies surrounding opposite signed anomalies in the eastern equatorial Atlantic (Fig. 3c). The Atlantic Niño, NTA, and HS pattern are well separated according to the North criterion (North et al. 1982), explaining the $37.79 \%, 19.23 \%$, and $11.95 \%$ of the total variance respectively.

Nevertheless, the frequency and amplitude of these modes is not stable, and its occurrence depends on the AMO phase. During negative AMO, the Atlantic Niño presents stronger and a westward extension of the equatorial SST anomalies (Fig. 3d). Moreover, it accounts a larger fraction of the total variance $(37.03 \%)$. The HS shows up as the second variability mode (18.86\% of the explained variance; Fig. 3e), relegating the NTA-like pattern to the third mode $(14.11 \%$ of the total variance; Fig. $3 f$ ). Under positive AMO phases, the largest fraction of TAV is shared between the Atlantic Niño and NTA patterns (36.44\% and $23.92 \%$ explained variance, respectively). A south tropical Atlantic (STA)-like structure appears as the third variability mode (Fig. 3i). Again, the North criterion is verified (North et al. 1982), confirming the separation of these tropical patterns in each AMO phase.

The HS pattern seems to be favored during negative AMO phases, showing up as the third interannual mode 
(a) AtI3SST and AMO index 1870-2010

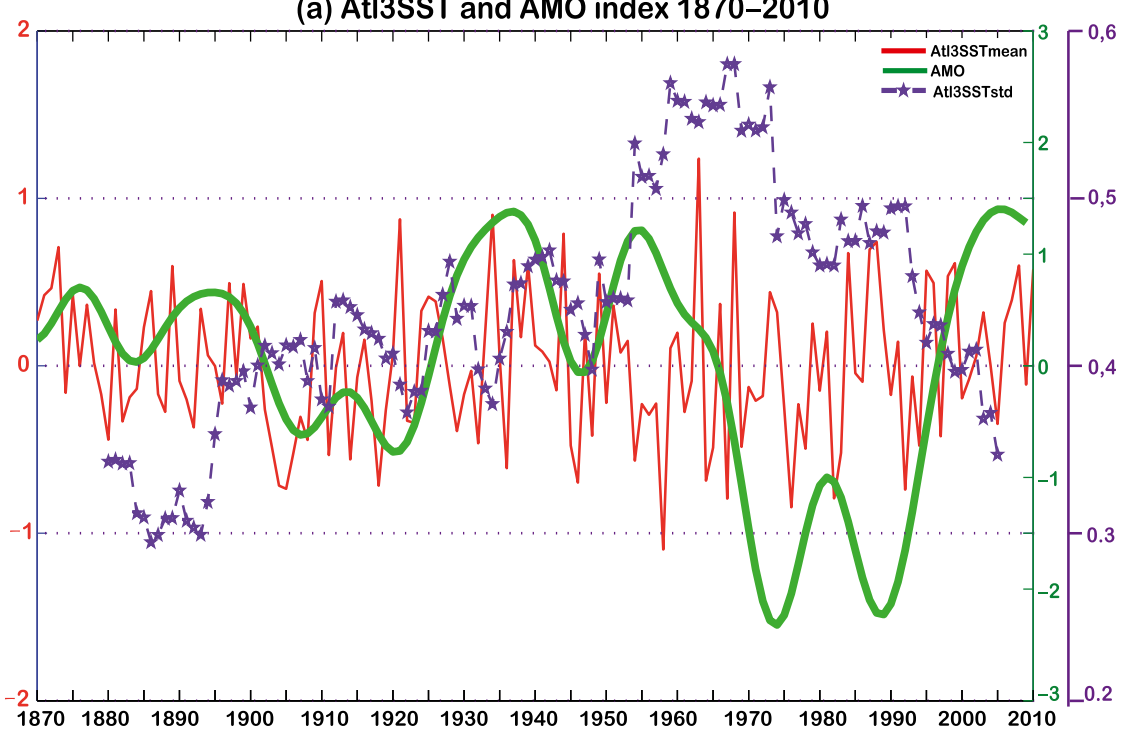

(b) varAtI3 AMOn/AMOp alpha=0.1 SpreadEns ctrI

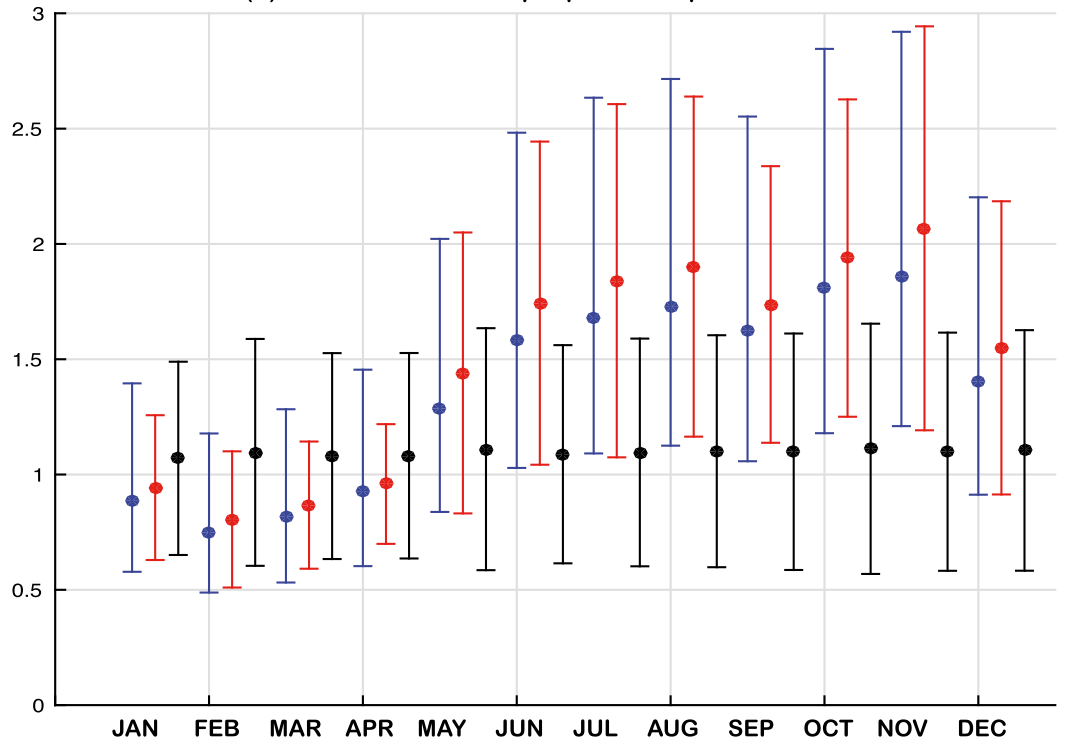

FIG. 1. (a) Mean and variability of the eastern equatorial Atlantic, Atl3 SST index $\left[4^{\circ} \mathrm{N}-4^{\circ} \mathrm{S}\right.$, $\left.20^{\circ} \mathrm{W}-0^{\circ} \mathrm{E}\right]$ in the twentieth century. Time evolution of the mean SST (red line) and standard deviation in 20-yr windows (purple dashed line) in the Atl3 region $\left[4^{\circ} \mathrm{N}-4^{\circ} \mathrm{S}, 20^{\circ} \mathrm{W}-0^{\circ} \mathrm{E}\right]$ from 1870 to 2014. The Atlantic multidecadal oscillation index is also shown (green line). (b) Variability of the equatorial Atlantic SST index depending on the AMO phase. Blue points indicate the ratio between the variance of equatorial Atlantic index for years of negative AMO phase and variance of equatorial Atlantic index for years of positive AMO phase for each calendar month. The AMO phase is valuated taking years above/below \pm 0.5 of the AMO index. The confidence interval based on an Fisher test ( $\mathrm{F}$ test) of equal variance at alpha $=0.1$ is plotted as an error bar. When the confidence level does not include the unit, the variances are significantly different. Red points are similar to blue points, but permuting randomly 10000 times the positive and negative years of the AMO phases, considering 20 years in each evaluation. Error bar shows the ensemble spread. The number and the pool of years considered of each AMO phase do not have an impact on the ratio of equatorial Atlantic variance. Black points indicate the same as red points but considering 20 years randomly over the observational period of each AMO phase. By chance, there is no significant change in the equatorial Atlantic variance. 
(a) DIF MEAN ANNUAL U200

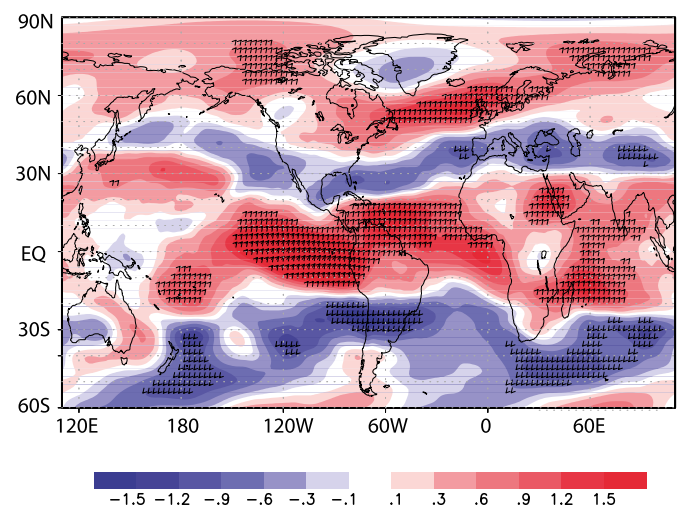

(c) DIF MEAN ANNUAL UWND

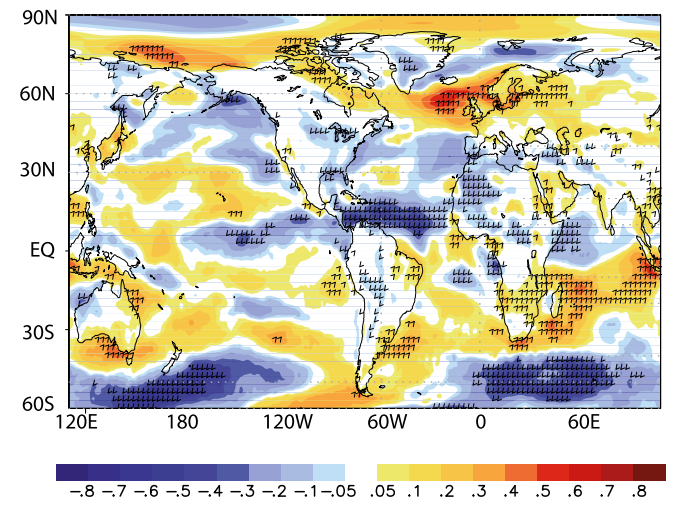

(e) DIF MEAN ANNUAL SST

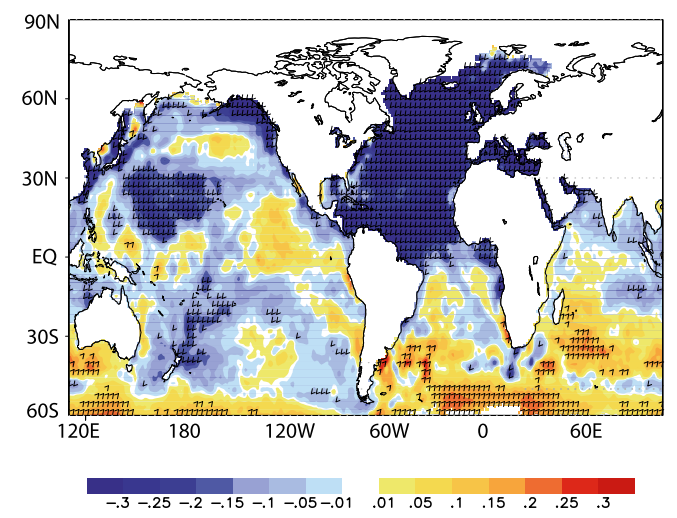

(b) DIF MEAN ANNUAL CHI200

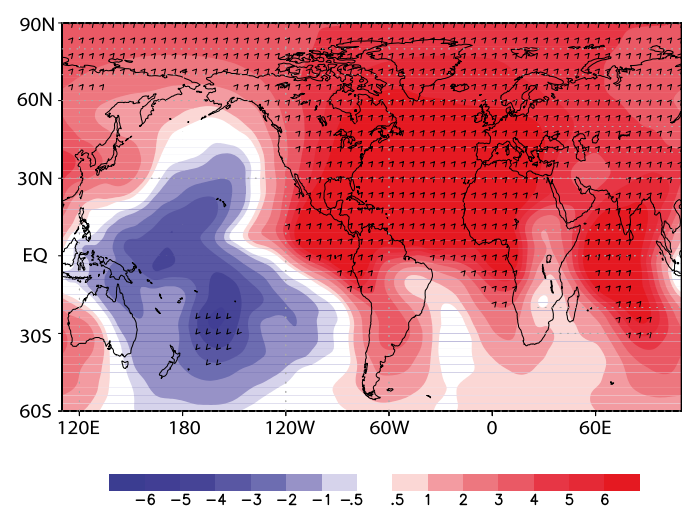

(d) DIF MEAN ANNUAL SLP

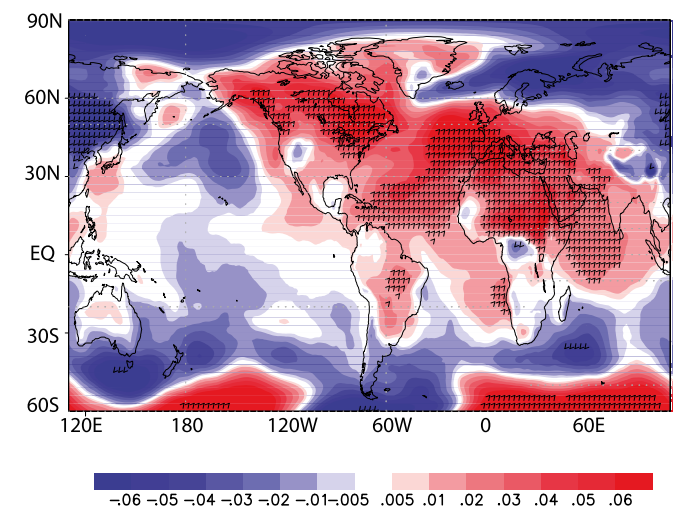

FIG. 2. Changes in the background state in negative vs positive AMO phases: differences between (a) annual zonal wind at $200 \mathrm{hPa}$, (b) velocity potential in upper levels (200 hPa), (c) surface zonal wind, (d) SLP, (e) SST, and (f) thermocline depth in negative AMO phases respect to positive ones. SST data come from HadISST (Rayner et al. 2003), thermocline depth is taken from SODA reanalysis (Giese and Ray 2011), and surface wind, SLP, and velocity potential are from ERA-20C reanalysis (Poli et al. 2013). Dotted areas denote significant values exceeding $95 \%$ confidence level according to a $t$ test of equal means.

along the entire observational record (Fig. 3c) but as the second mode in negative AMO phases (Fig. 3e). During negative AMO, the HS mode shows a structure that is independent of the NTA. This has been confirmed by lead-lag correlations between SST anomalies in different regions of the TA during those decades (Fig. 4). We have defined three boxes to describe the HS spatial pattern: SNTA $\left[5^{\circ}-10^{\circ} \mathrm{N}, 60^{\circ}-10^{\circ} \mathrm{W}\right]$, WEQ $\left[5^{\circ} \mathrm{N}-5^{\circ} \mathrm{S}\right.$, 
(a) EOF1 JJAS 1870-2014

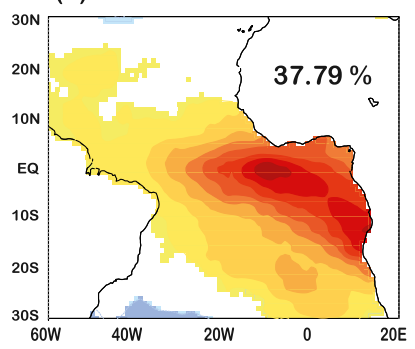

(b) EOF2 JJAS 1870-2014

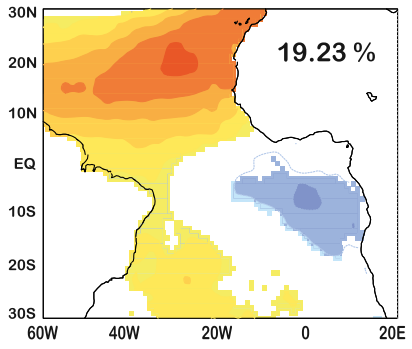

(c) EOF3 JJAS 1870-2014

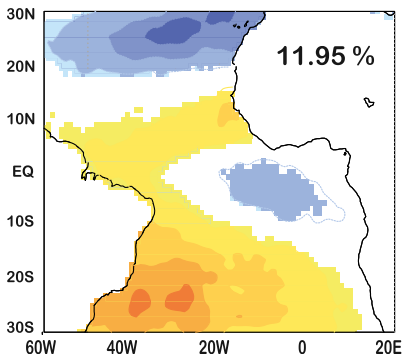

(d) EOF1 JJAS AMOneg

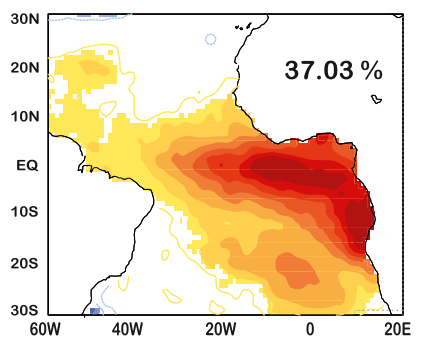

(e) EOF2 JJAS AMOneg

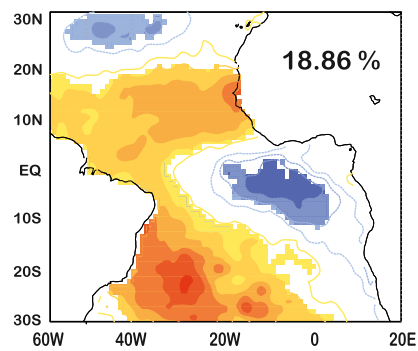

(f) EOF3 JJAS AMOneg

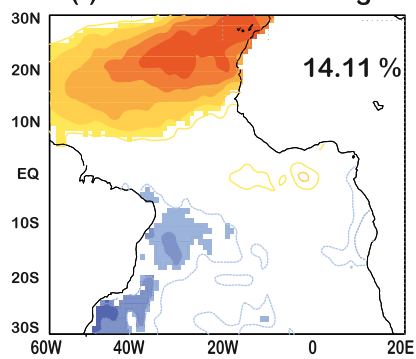

(g) EOF1 JJAS AMOpos

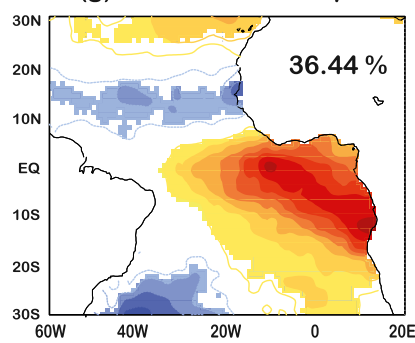

(h) EOF2 JJAS AMOpos

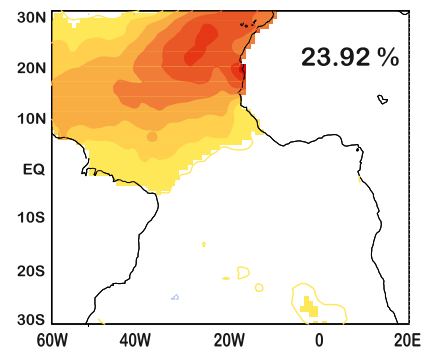

(i) EOF3 JJAS AMOpos

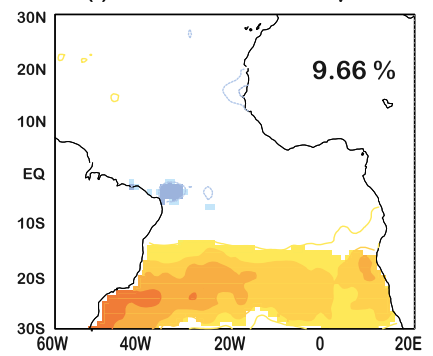

FIG. 3. Modes of interannual SST variability in the tropical Atlantic. Regression maps of the anomalous SSTs for the first three empirical orthogonal functions (EOFs) of interannual tropical Atlantic $\left[30^{\circ} \mathrm{N}-30^{\circ} \mathrm{S}, 60^{\circ} \mathrm{W}-20^{\circ} \mathrm{E}\right]$ variability in June-September (JJAS) for (a)-(c) the total period 1870-2014 and the (d)-(f) negative and (g)-(i) positive AMO phases. Significant values exceeding 95\% confidence level according to a Monte Carlo test are shown shaded, while the total regression field is presented in contours.

$\left.50^{\circ}-30^{\circ} \mathrm{W}\right]$, and WSTA $\left[10^{\circ}-30^{\circ} \mathrm{S}, 40^{\circ}-10^{\circ} \mathrm{W}\right]($ Fig. $4 \mathrm{a})$. The NTA mode is depicted by a unique box in the northern part of the TA basin: NNTA $\left[20^{\circ}-30^{\circ} \mathrm{N}, 60^{\circ}-\right.$ $10^{\circ} \mathrm{W}$ ] (Fig. 4b). Notice that the analysis has been restricted to those areas representative of the NTA and HS modes. The latitudinal band between $10^{\circ}$ and $20^{\circ} \mathrm{N}$ has been avoided since it could belong to both patterns.

Positive and significant correlations are found between the principal component of the HS mode and the regions surrounding the eastern equatorial Atlantic (blue, red, and purple boxes in Fig. 4a) from the winter before the peak of the mode to the following fall (Fig. 4c). Similar results are attained for NNTA SST anomalies and the NTA mode (blue line, Fig. 4d). This corroborates that SNTA, WEQ, and WSTA define correctly the HS structure, while NNTA is the key region to describe the NTA mode. Moreover, very low (close to zero) correlation scores between the HS pattern and NNTA anomalous SSTs are shown at all lags (blue line, Fig. 4c), revealing a lack of connection between the HS and NTA modes along their development and decay. Similar results are obtained when the NTA pattern is correlated to the SNTA, WEQ, and WSTA regions (red, purple, and green lines, Fig. 4d). We conclude that during negative AMO phases there are two different and independent modes that define the SST variability in the north tropical region: the HS and the NTA patterns.

The abovementioned results evidence that during negative AMO phases the interannual TAV has increased, favoring the emergence of a new variability mode, the HS pattern. This finding has been also confirmed with several additional analyses: 1) using other SST datasets, ERSST (Huang et al. 2015) and SODA (Giese and Ray 2011);2) doing composites instead of regressions for HS and NTA; 3 ) considering different 


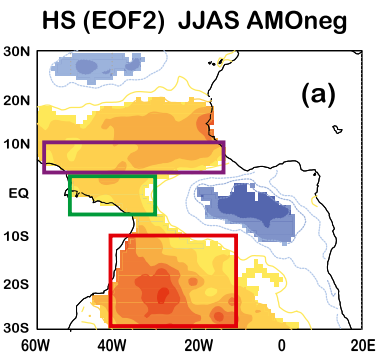

(c) Lead-Lag corr TA indices - HS mode AMOneg

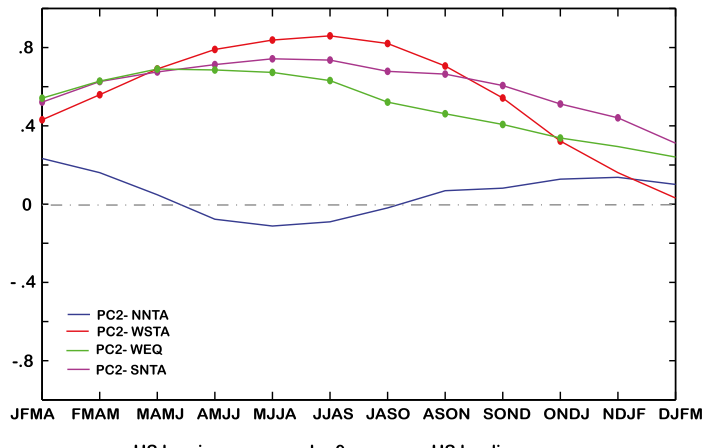

HS lagging

$\operatorname{lag} 0$

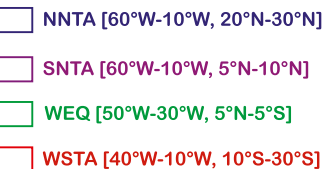

NTA (EOF3) JJAS AMOneg

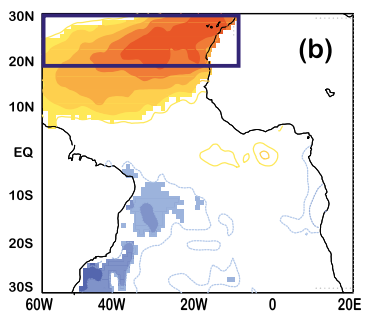

(d) Lead-Lag corr TA indices - NTA mode AMOneg

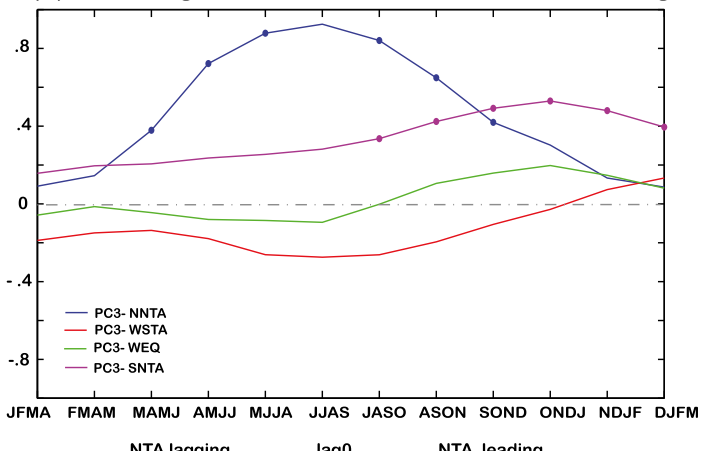

FIG. 4. Indices characterizing the (a) horseshoe (HS) and (b) NTA modes in negative AMO phases. Also shown is the lead-lag correlation between the boreal summer (JJAS) (c) HS mode and (d) NTA pattern and the anomalous SSTs in NNTA [20 - $30^{\circ} \mathrm{N}, 60^{\circ}-$ $\left.10^{\circ} \mathrm{W}\right]$, (blue line), SNTA $\left[5^{\circ}-10^{\circ} \mathrm{N}, 60^{\circ}-10^{\circ} \mathrm{W}\right]$, (purple line), WEQ $\left[5^{\circ} \mathrm{N}-5^{\circ} \mathrm{S}, 50^{\circ}-30^{\circ} \mathrm{W}\right]$, (green line), and WSTA $\left[10^{\circ}-30^{\circ} \mathrm{S}, 40^{\circ}-10^{\circ} \mathrm{W}\right]$ (red line) from JFMA (lag -5) to DJFM (lag +6). Dots indicate the significant correlation scores exceeding $95 \%$ confidence level according to a $t$ test.

climatological periods; and 4) applying the extended EOF technique (not shown).

To better understand the decadal variations experienced by the TAV interannual modes, the following sections are devoted to exploring their atmospheric forcings, and the possible role played by the background state in each AMO phase.

\section{c. Changes in the Atlantic Niño in different AMO phases}

\section{1) Development of the Atlantic Niño}

Under negative AMO phases, the evolution of the Atlantic Niño starts with anomalous northwesterly winds in the STA $\left[5^{\circ}-30^{\circ} \mathrm{S}, 30^{\circ} \mathrm{W}-10^{\circ} \mathrm{E}\right]$ in NovemberFebruary (NDJF) (year -1 ). These surface winds are part of a large-scale weakening of the southern trades that is prolonged during the following seasons (Figs. 5a,b). As a consequence, a reduction in the evaporative heat loss would warm the sea surface (Figs. 5a-c). Notice that, preceding the Atlantic Niño phenomenon, anomalous positive SSTs arise along the Angola-Benguela coast, peaking in boreal spring (Figs. 5a-c; Polo et al. 2008; Lübbecke et al. 2010). This Benguela Niño (Shannon et al. 1986) could be caused by local air-sea interactions associated with anomalous southward alongshore winds (Polo et al. 2008) from NDJF to January-April (JFMA) (Figs. 5a,b). The western equatorial wind forcing (Figs. 5b,c) could also excite equatorial Kelvin waves that propagate along the southern African coast, contributing to the Benguela warming (Lübbecke et al. 2010). A progressive general weakening of the northern trades from JFMA (Figs. 5b,c) could warm the northwestern TA through turbulent heat fluxes (Wagner 1996; Chang et al. 1997; Amaya et al. 2017). At the equator, anomalous westerly winds from late winter (JFMA) could deepen the thermocline in the central-eastern equatorial Atlantic. This could, in turn, activate the Bjerknes feedback (Bjerknes 1969; Keenlyside and Latif 2007) and favor the development of the warm tongue (Figs. 5b-d). Thermodynamic processes, related to the suppressed evaporation in STA and equatorial region, could also be also relevant to generate the Atlantic Niño SST pattern (Nnamchi et al. 2015, 2016).

Under positive AMO phases, an intensification of the northeasterly trades in previous winter (NDJF; Fig. 5e) generates the onset of the Atlantic Niño phenomenon. These strengthened winds could enhance the evaporation through latent heat fluxes (Carton et al. 1996; 
(a) EOF1-SST WIND NDJF y(-1) AMOneg

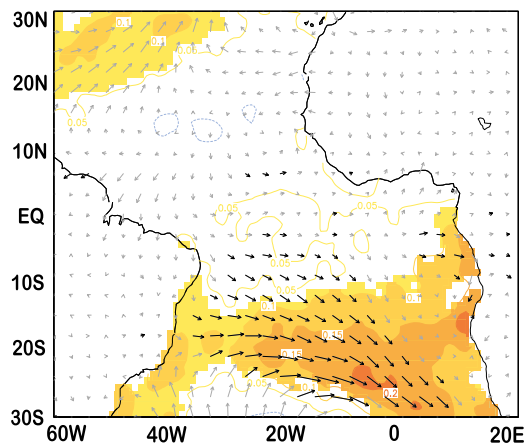

(b) EOF1-SST WIND JFMA y(0) AMOneg

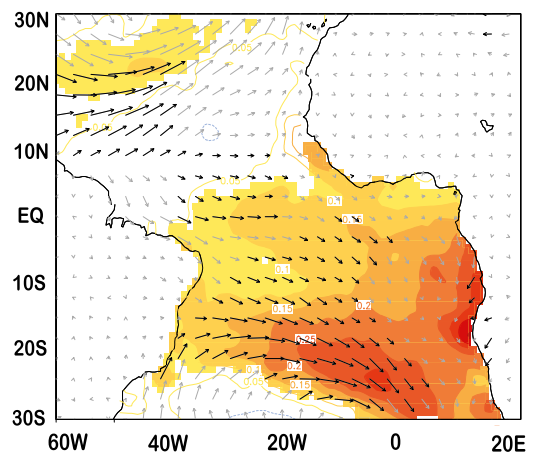

(c) EOF1-SST WIND MAMJ y(0) AMOneg

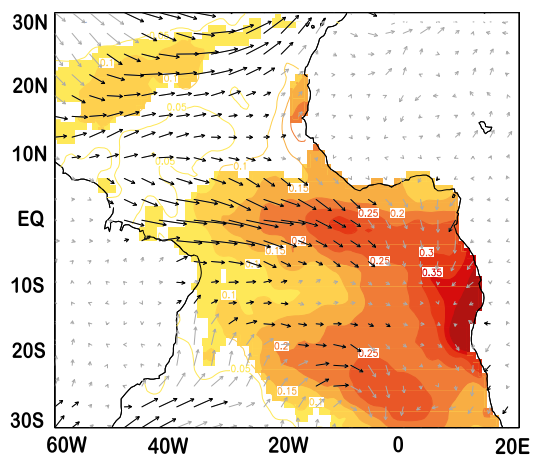

(d) EOF1-SST WIND JJAS y(0) AMOneg

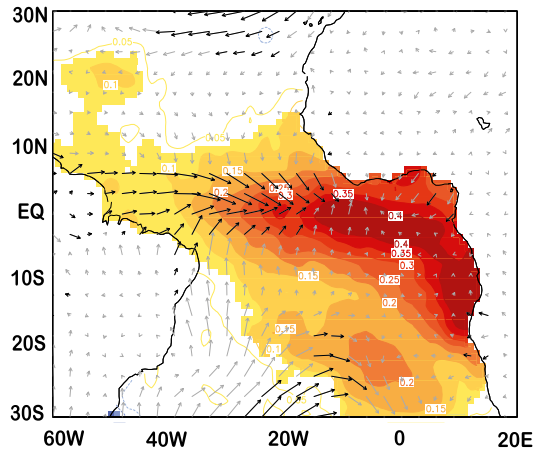

(e) EOF1-SST WIND NDJF y(-1) AMOpos

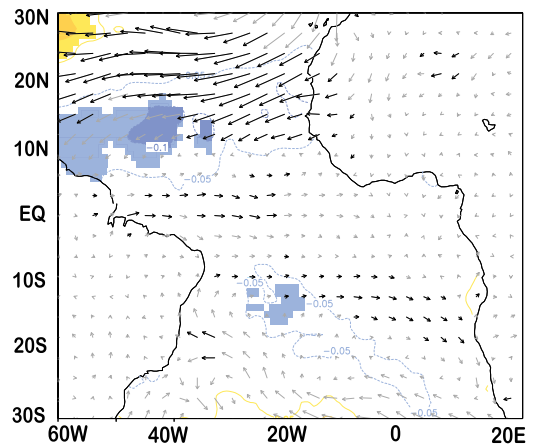

(f) EOF1-SST WIND JFMA y(0) AMOpos
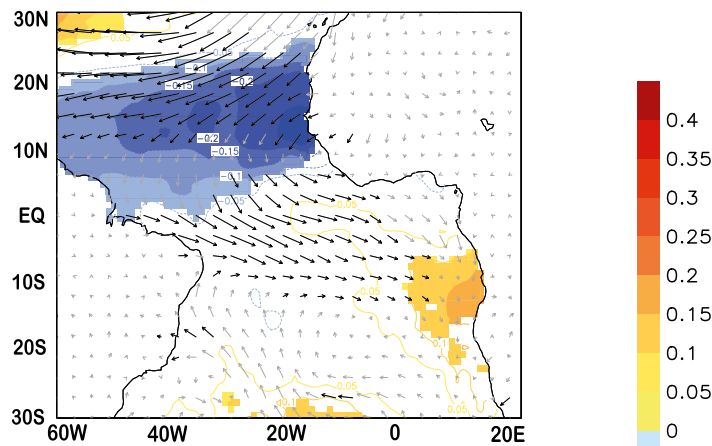

(g) EOF1-SST WIND MAMJ y(0) AMOpos

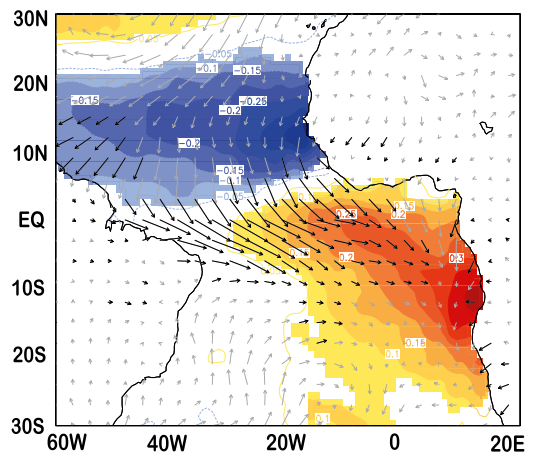

(h) EOF1-SST WIND JJAS y(0) AMOpos

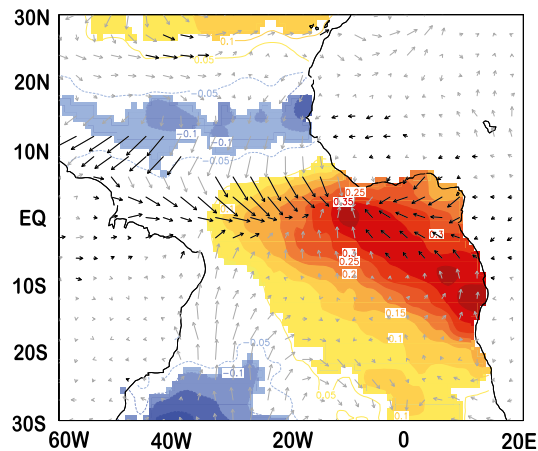

FIG. 5. Regression maps of the seasonal SST and surface wind anomalies over the Atlantic Niño from NDJF (year -1) to JJAS (year 0) for (left) negative and (right) positive AMO periods. Significant values exceeding 95\% confidence level according to a $t$ test are shown shaded and by black vectors. The total regression SST and wind field are presented in contours and gray vectors respectively. 
Wagner 1996), cooling the NTA region (Figs. 5e,f). Concomitant southeasterly winds close to the AngolaBenguela region could cause the deepening of the local thermocline (Polo et al. 2008). Additionally, anomalous westerly winds in the equatorial band could also trigger oceanic Kelvin waves, which propagates along the coast impacting the Angola-Benguela thermocline (Lübbecke et al. 2010). Both processes would involve a reduction of the coastal upwelling and the warming of the sea surface (Figs. 5f,g). During boreal spring, an interhemispheric SST pattern develops (Fig. 5g), resembling the negative phase of the meridional mode (Ruiz-Barradas et al. 2000; Chiang and Vimont 2004). This dipole SST configuration could intensify the C-shaped wind pattern (Fig. 5g), enhancing (reducing) the evaporative heat loss in the NTA (STA). Accordingly, the initial SST gradient reinforces, establishing the WES feedback (Chang et al. 1997; Amaya et al. 2017). At the equator, weaker trades could decrease the thermocline tilt, inhibiting the equatorial upwelling and setting up the conditions for the warm tongue development (Figs. 5g,h). Wind-induced turbulent heat fluxes could also contribute to generate the Atlantic Niño SST anomalies (Nnamchi et al. 2015, 2016).

A remarkable result is the different configuration of the Atlantic Niño in positive and negative AMO periods. For positive AMO phases, the positive SSTs are restricted to the eastern equatorial Atlantic, while an anomalous cooling appears in the western STA (Fig. 5h). This dipolelike structure is consistent with the Atlantic Niño pattern found before the 1970s (Rodríguez-Fonseca et al. 2009; Losada et al. 2012b; Martín-Rey et al. 2014; Losada and Rodríguez-Fonseca 2016). It also resembles the summer footprint of the South Atlantic Ocean dipole (SAOD) (Nnamchi et al. 2011, 2016). On the contrary, a basinwide Atlantic Niño configuration, with stronger eastern equatorial warming, is observed during negative AMO phases (Fig. 5d). This structure is in agreement with the Atlantic Niño pattern also reported in previous studies (Polo et al. 2008; Rodríguez-Fonseca et al. 2009; Martín-Rey et al. 2014; Losada and Rodríguez-Fonseca 2016). The westward extension of the Atlantic Niño warm tongue could shift the location of the maximum equatorial convection (Figs. 5d,h) and consequently modify the Atlantic Niño teleconnections (Losada and Rodríguez-Fonseca 2016).

It is worth mentioning that during positive AMO phases, the Atlantic Niño is preceded by a negative meridional mode pattern (Fig. $5 \mathrm{~g}$ ). The possible interaction between both phenomena has been proposed in previous studies (Servain et al. 1999; Andreoli and Kayano 2003; Foltz and McPhaden 2010; Zhu et al. 2012). On the one hand, the meridional ITCZ displacement associated with the meridional mode could reinforce the equatorial winds, changing the thermocline tilt and favoring the development of the Atlantic Niño (Servain et al. 1999; Murtugudde et al. 2001). On the other hand, the connection between the meridional mode and the Atlantic Niño could be determined by the interaction between the directly wind-forced equatorial Kelvin waves and the boundary reflected Rossby waves (Foltz and McPhaden 2010). More recently, Zhu et al. (2012) suggested that the transition between modes could be carried out by the discharge of the off-equatorial heat content into the equatorial waveguide. According to our results, the connection between the interannual modes could be also modulated by the low-frequency variability, through changes either in the TA mean state or in the spatial interannual patterns (Figs. $5 \mathrm{~d}, \mathrm{~g}$ ).

The abovementioned results, together with the current controversy about the thermodynamical versus dynamical origin of the Atlantic Niño (Keenlyside and Latif 2007; Richter et al. 2013; Nnamchi et al. 2016), demonstrate that further research is still required. For instance, a proper head budget analysis of the Atlantic Niño mode, as in Polo et al. (2015b), needs to be computed for different AMO periods. Furthermore, the role played by the boreal spring interannual variability in the development of the Atlantic Niño should be also determined.

\section{2) Atmospheric FORCING OF THE AtLANTIC NiÑO}

To understand the differences in the structure of the Atlantic Niño (Fig. 3), the contribution of the subtropical high pressure systems during its development has been examined for different AMO periods (Fig. 6). In negative AMO periods, a simultaneous weakening of the St. Helena and Azores high during winter and spring leads the occurrence of Atlantic Niño events (Figs. 6a,b). The anomalous SLP causes a general reduction of the tropical trades, which in turn contribute to generate the anomalous SST pattern (Figs. 5a,d). For positive AMO periods, before the peak of the Atlantic Niño an intensified Azores high coexists with anomalous low pressure conditions in the eastern STA (Fig. 6c). This meridional SLP dipole reinforces the northern trades and originates northward cross-equatorial winds during boreal winter (Figs. 5e-h). The pattern evolves into a zonal SLP gradient during the spring season, intensifying the equatorial westerly winds (Fig. 6d) and supporting the Atlantic Niño SST pattern (Figs. 5e-h).

Our results are in agreement with recent findings that underline the influence of the South Atlantic Anticyclone in the development of the Atlantic Niño phenomenon (Polo et al. 2008; Lübbecke et al. 2010; Richter et al. 2010; Lübbecke et al. 2014). Nevertheless, here we provide new insights in the role played by the large-scale pressure 
(a) EOF1-SLP WIND JFMA y(0) AMOneg

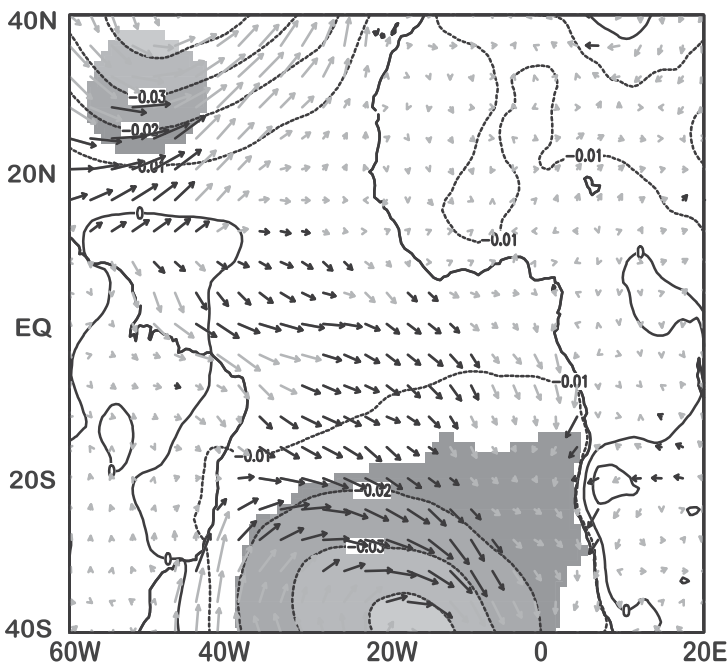

(b) EOF1-SLP WIND MAMJ y(0) AMOneg
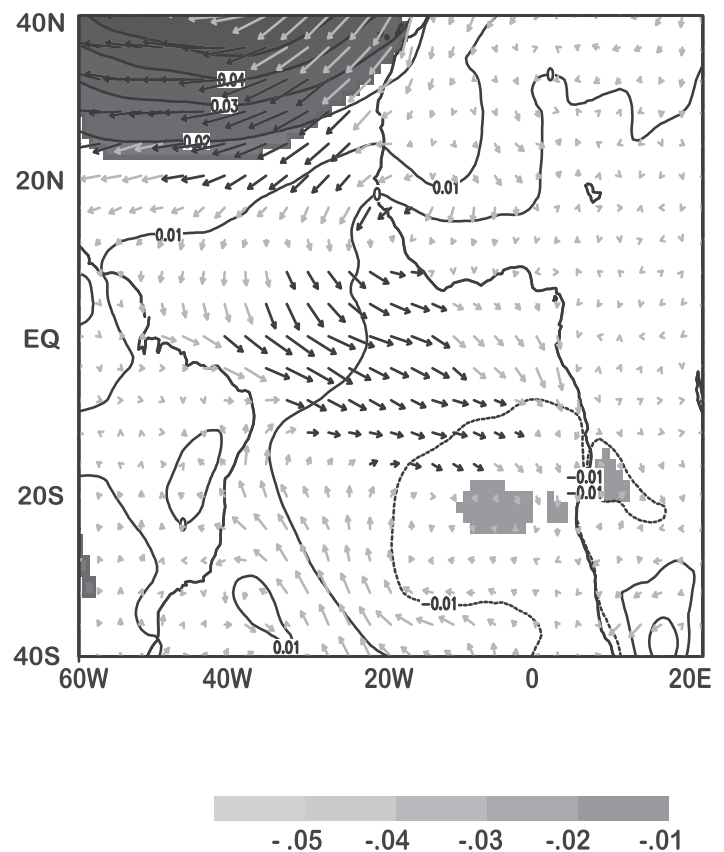

(c) EOF1-SLP WIND JFMA y(0) AMOpos

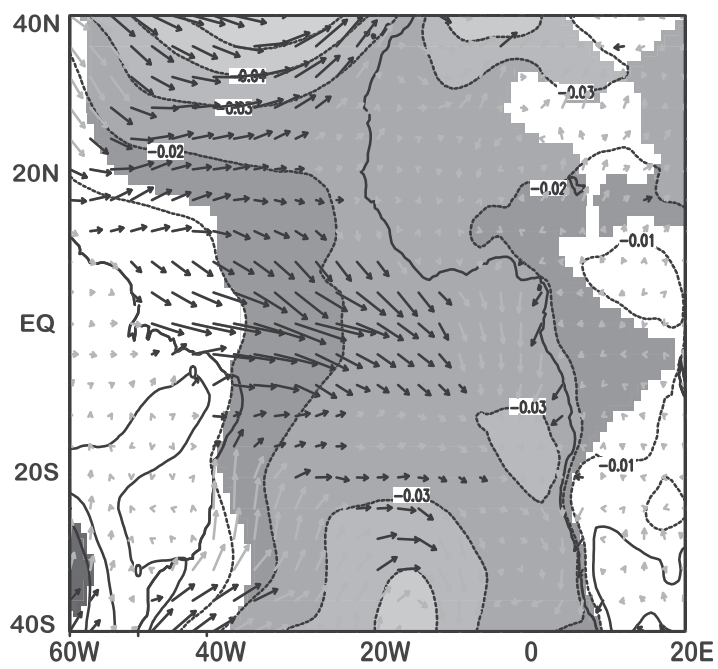

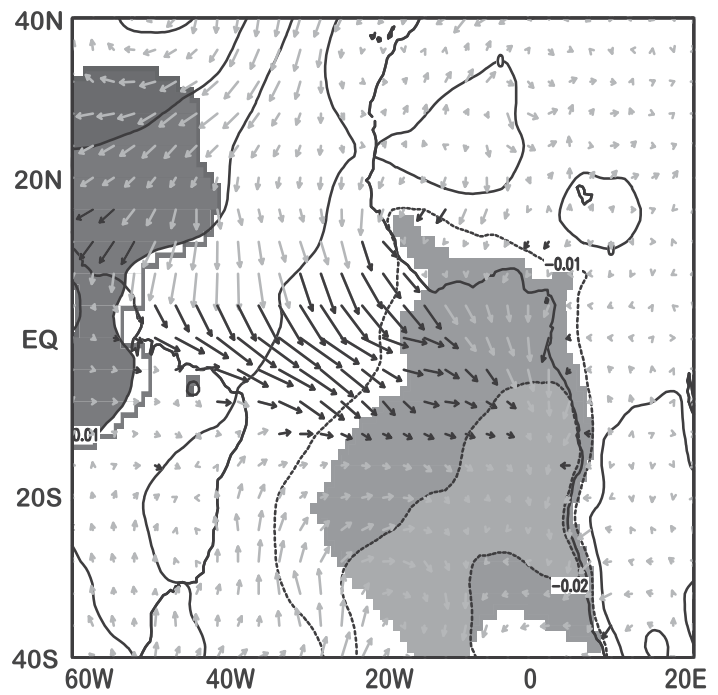

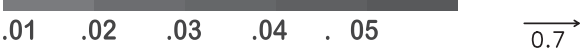

FIG. 6. (a)-(d) Regression maps of the seasonal SLP and surface wind anomalies over the Atlantic Niño in JFMA (year 0) and March-June (MAMJ) (year 0) in (left) negative and (right) positive AMO phases. Significant values exceeding 95\% confidence level according to a $t$ test are shown in shaded and black vectors. The total regression SLP and wind field are presented in contours and gray vectors respectively.

systems: according to our results, both subtropical highs are necessary to generate the Atlantic Niño. Moreover, the different interaction between the Azores and St. Helena high seems to be crucial to define the Atlantic Niño spatial configuration during different AMO phases.

\section{3) BACKGROUND CHANGES RELATED TO THE ATLANTIC NIÑO}

Apart from the atmospheric forcings, the Atlantic background state could also contribute to the modification of 
the Atlantic Niño pattern under different AMO periods. Negative AMO phases present cooler SST conditions (Fig. 2e) and a shallower thermocline depth in the central-eastern equatorial Atlantic (Fig. 2f), compared to positive AMO periods. This increase in the thermocline slope could constitute a more efficient Bjerknes feedback (Bjerknes 1969) over the equator, thus enhancing the equatorial SST variability (Fig. 1b). Consequently, stronger SST anomalies could develop in the Atlantic Niño warm tongue (Fig. 5d). Strengthened westward winds along the equatorial band (Fig. 2c), together with a deeper thermocline in the western TA (Fig. 2f), could favor the westward extension of the Atlantic Niño warm tongue during negative AMO phases.

\section{d. NTA pattern depending on the AMO phase}

It is clear from Fig. 3 that, during negative AMO phases, two different and separated modes define the boreal summer north tropical Atlantic SST variability: NTA and the HS patterns (Figs. 3e,f). On the contrary, in positive AMO phases only one mode, the NTA pattern, dominates it. In this section we investigate the NTA pattern depending on AMO periods, describing its spatial configuration and analyzing the associated atmospheric forcing.

\section{1) Development of THE NTA PATTERN}

In negative AMO phases, the NTA mode is initiated by anomalous westerly winds that appear in the northern tropics $\left(20^{\circ}-30^{\circ} \mathrm{N}\right)$ during winter (JFMA; Fig. 7a). Weakened trades north of $10^{\circ} \mathrm{N}$ during spring could diminish the latent heat loss (Carton et al. 1996; Wagner 1996; Chang et al. 1997), warming the underneath area (Figs. 7a,b). A positive feedback between the SST and surface wind anomalies (Amaya et al. 2017) could give rise to the NTA mode in boreal summer (Fig. 7c).

For positive AMO periods, the anomalous reduction of the northern trades in winter appears accompanied by anomalous westerlies near the Mauritanian-Senegal coast (Figs. 7d,e). These local winds could cause the thermocline to deepen, inhibiting the coastal upwelling and promoting the sea surface warming (Figs. 7d,e). However, recent studies have also stated the substantial contribution of surface heat fluxes in the northwest African coastal SST variations (Oettli et al. 2016). Offshore positive SST anomalies could be produced by a decrease in the wind-induced evaporation (Figs. 7d,e). The NTA structure during boreal spring resembles the northern branch of the meridional mode (Ruiz-Barradas et al. 2000), which is linked to a northward displacement of the ITCZ (Chiang and Vimont 2004). From spring to summer months, the SST anomalies are intensified, probably due to a positive air-sea feedback between the north and the tropics (Fig. 7f).

2) LARGE-SCALE FORCING AND MULTIDECADAL MODULATION OF THE NTA PATTERN

An important feature is that, depending on the AMO phase, the NTA pattern is different along the northwest African upwelling system (Fig. 7). These coastal SST anomalies seem to represent an important part of the NTA variance (Polo et al. 2005) only during positive AMO periods. For negative AMO phases, there is a northward shift of the NTA anomalies that could be due to diverse atmospheric forcing. Well-defined weather regimes over the North Atlantic force the NTA pattern in both AMO phases, via changes in the Azores high (Fig. 8). During negative AMO, there is a seesaw pattern of SLP between the North Atlantic and European sector, similar to the Scandinavian blocking (Cassou 2008; Peings and Magnusdottir 2014), leading the development of NTA mode (Fig. 8a). Under positive AMO, however, the NTA is part of the southern branch of the SST tripole pattern (see Fig. S1 in the online supplemental material). This SST configuration is associated with the NAO (Hurrell et al. 2001; Rodríguez-Fonseca and de Castro 2002) and the latitudinal migration of the ITCZ (Chiang and Vimont 2004). A possible explanation for these different atmospheric forcing could be a modification of the North Atlantic weather regimes under both AMO phases. Some authors have attributed positive AMO conditions to negative NAO-like patterns (Peings and Magnusdottir 2014; Davini et al. 2015). Thus, for positive AMO periods, an increase of the frequency of winter negative NAO structures (Fig. 8c) could favor the development of the NTA mode characteristics (Fig. 7f).

Our results do not shown any relationship between the NTA pattern and the ENSO phenomenon during positive AMO periods, in contrast to Wang et al. (2017). These discrepancies could be attributed to the different timing between the NTA patterns considered: Wang et al. (2017) studied boreal spring, whereas we focus on the boreal summer mode. Moreover, Wang et al. (2017) claim that the NTA-ENSO link is only found in the most recent positive AMO phase (after the mid-1990s), favored by the global warming trend. However, further research needs to be done for a better comprehension of the extratropical forcings and impacts of the NTA pattern.

\section{e. Emergence of the HS mode in negative AMO phases}

During negative AMO periods, the variability of the NTA is combined with the southwesterly one to generate a new dominant TAV mode: the HS pattern. The development of the HS configuration, its remote 
(a) EOF3-SST WIND JFMA y(0) AMOneg

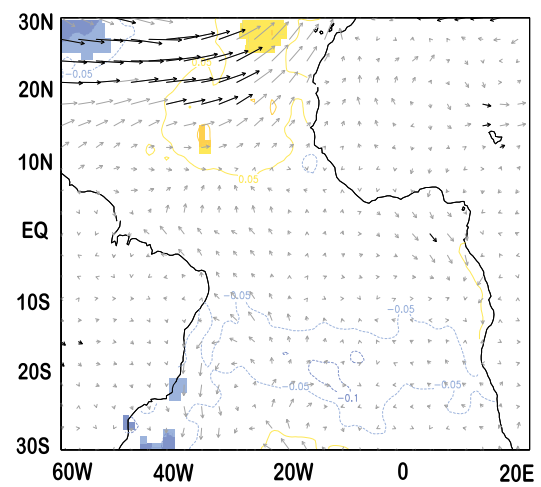

(b) EOF3-SST WIND MAMJ y(0) AMOneg

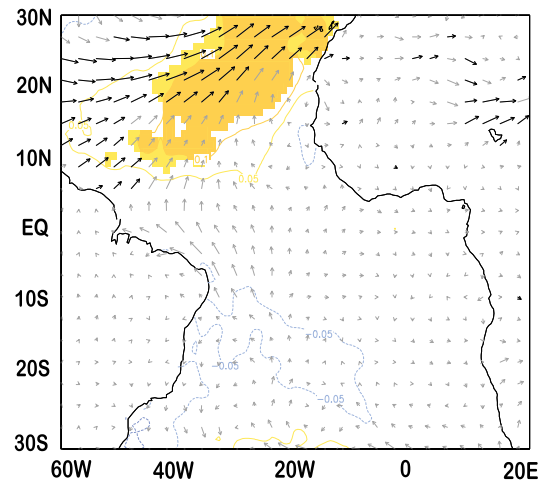

(c) EOF3-SST WIND JJAS y(0) AMOneg

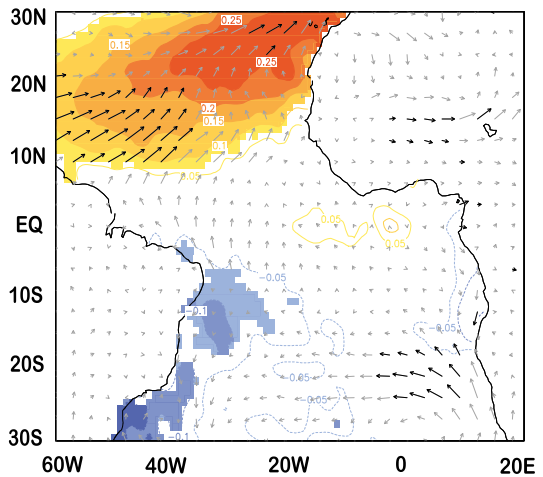

(d) EOF2-SST WIND JFMA y(0) AMOpos

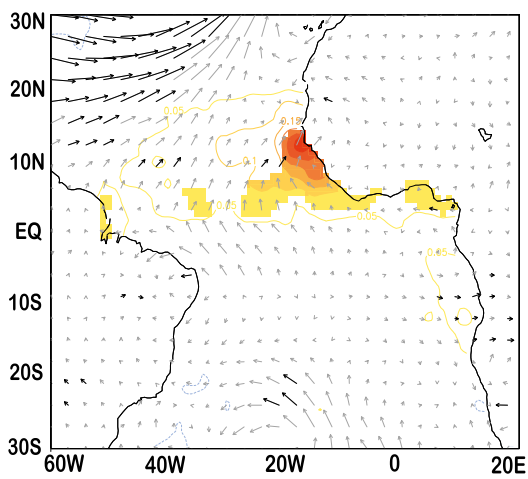

(e) EOF2-SST WIND MAMJ y(0) AMOpos

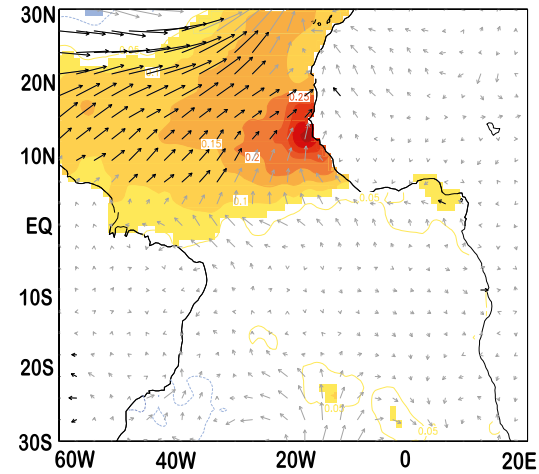

(f) EOF2-SST WIND JJAS y(0) AMOpos

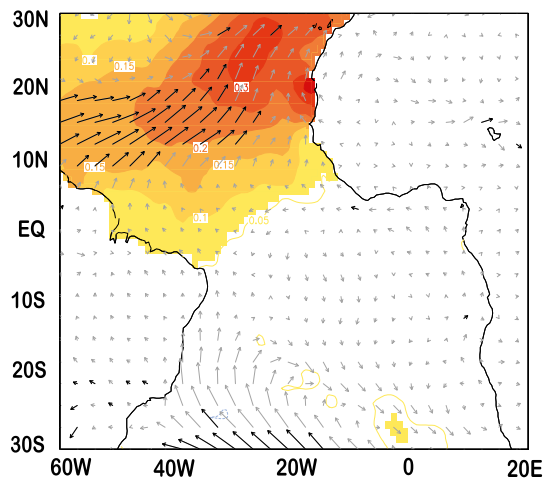

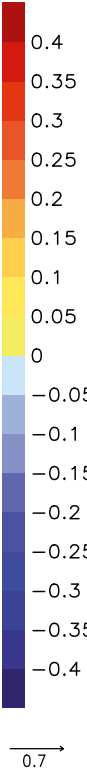

FIG. 7. Regression maps of the seasonal SST and surface wind anomalies over the NTA pattern from JFMA (year 0 ) to JJAS (year 0) for (left) negative and (right) positive AMO periods. The total regression fields for the tropical surface wind and SST are presented in gray vectors and contours respectively. Significant values exceeding $95 \%$ confidence level according to a $t$ test are shown in shaded and black vectors.

atmospheric forcing, and the causes for its emergence are assessed in this section.

\section{1) DEVELOPMENT OF THE HS PATTERN}

The onset of the HS mode takes place in DecemberMarch (DJFM) with anomalous trades in the NTA and
STA regions (Fig. 9a). As a consequence, the wind-induced evaporative heat loss would be reduced (Carton et al. 1996; Wagner 1996), warming the tropics during later winter and early spring (Figs. 9a,b). Next to the northwest African coast, anomalous northward winds could reduce the upwelling, warming the coastal area (Figs. 9b,c). In addition, 
(a) EOF3-SLP WIND JFMA y(0) AMOneg

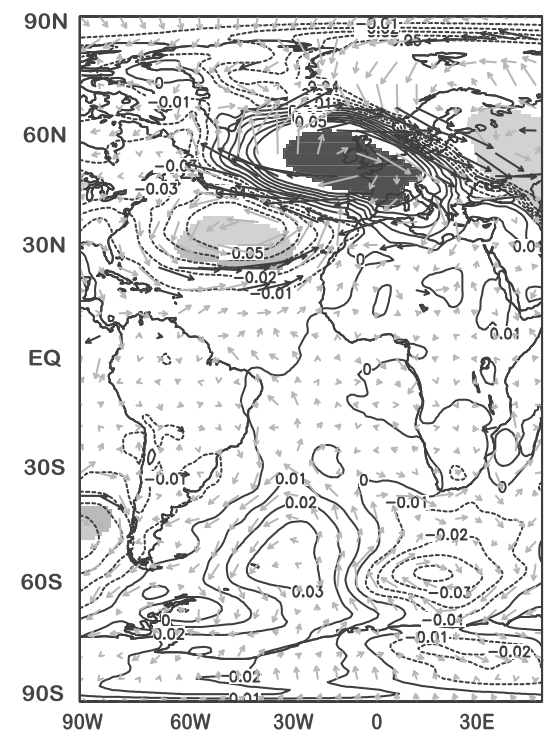

(b) EOF3-SLP WIND MAMJ y(0) AMOneg

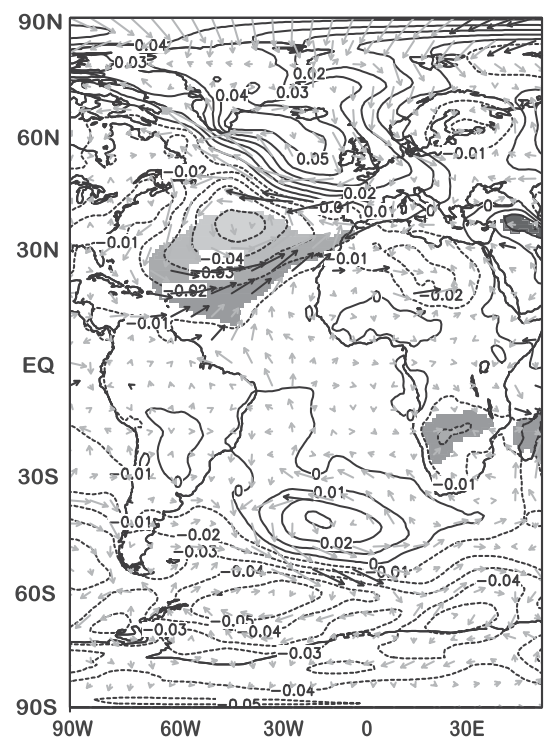

(c) EOF2-SLP WIND JFMA y(0) AMOpos

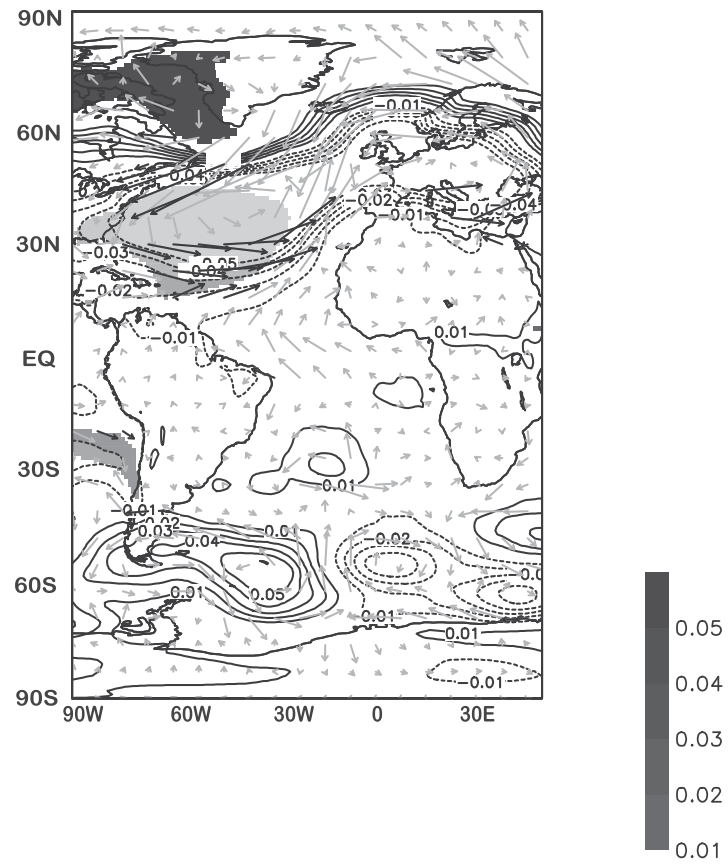

(d) EOF2-SLP WIND MAMJ y(0) AMOpos

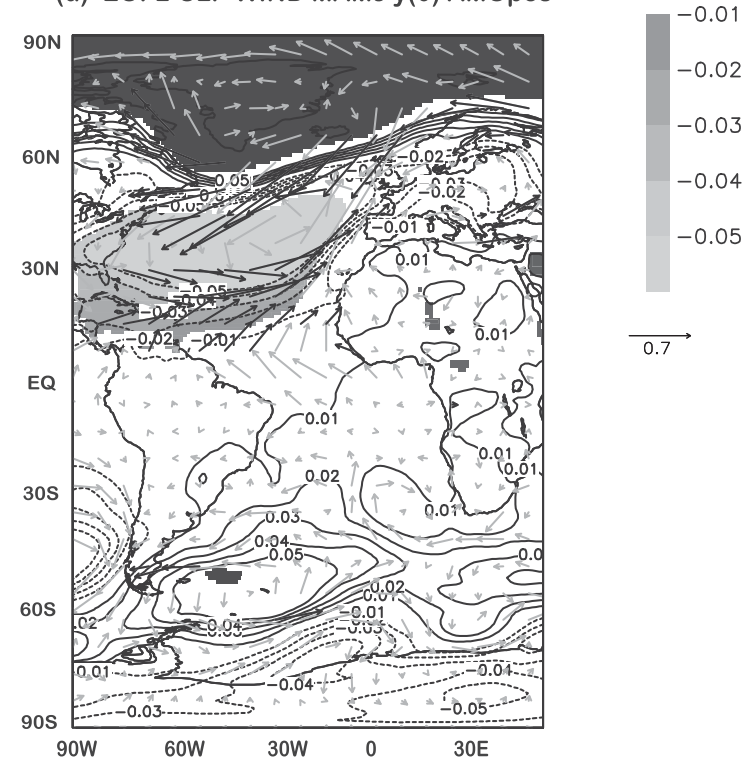

FIG. 8. (a)-(d) Regression maps of the NTA pattern over the SLP and surface wind in JFMA and MAMJ for (left) negative and (right) positive AMO phases. Significant values at 95\% confidence level according to a Student's $t$ test are shown in shaded and black vectors. Total regression SST and wind field are also presented in contours and gray vectors.

the absorption of shortwave radiation by a thinner mixed layer could also enhance the coastal warming (Oettli et al. 2016). Along the equatorial band, the easterly winds are intensified from winter to spring. This could increase the upwelling of cold deep waters to the surface, generating the cold tongue in the east (Figs. 9b,c). During summer months, the central-eastern cooling could cause anomalous wind divergence (Fig. 9d), establishing a positive feedback (Bjerknes 1969). Notice that SST anomalies seem to peak during boreal spring and not in summer months (Figs. 9c,d).

\section{2) ENSO FORCING OF THE HS MODE}

The Atlantic Niño and NTA pattern are observed in both AMO periods. However, the emergence of the HS 
(a) EOF2-SST WIND DJFM y(-1) AMOneg

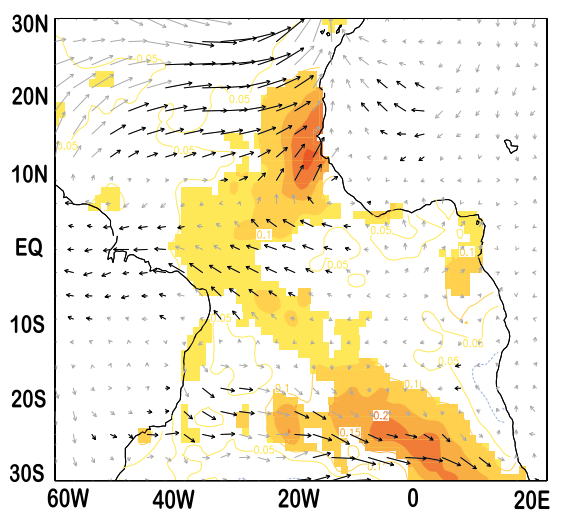

(c) EOF2-SST WIND AMJJ y(0) AMOneg

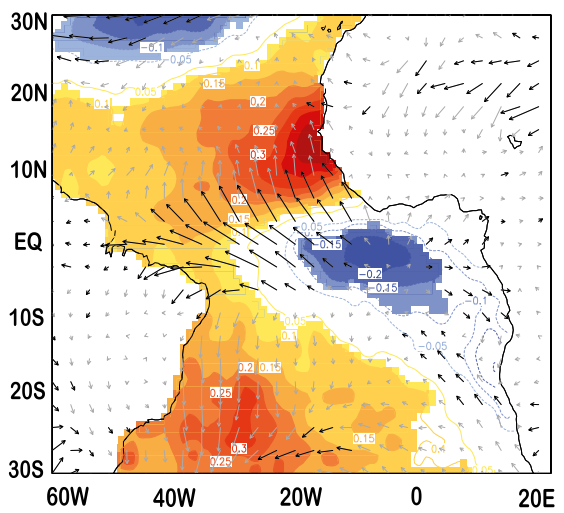

(b) EOF2-SST WIND FMAM y(0) AMOneg

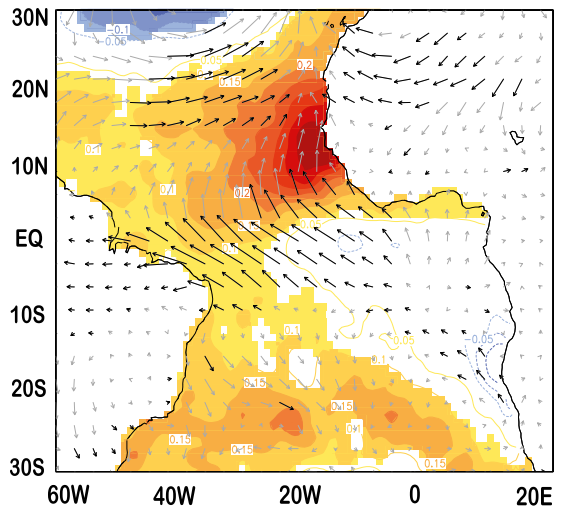

(d) EOF2-SST WIND JJAS y(0) AMOneg

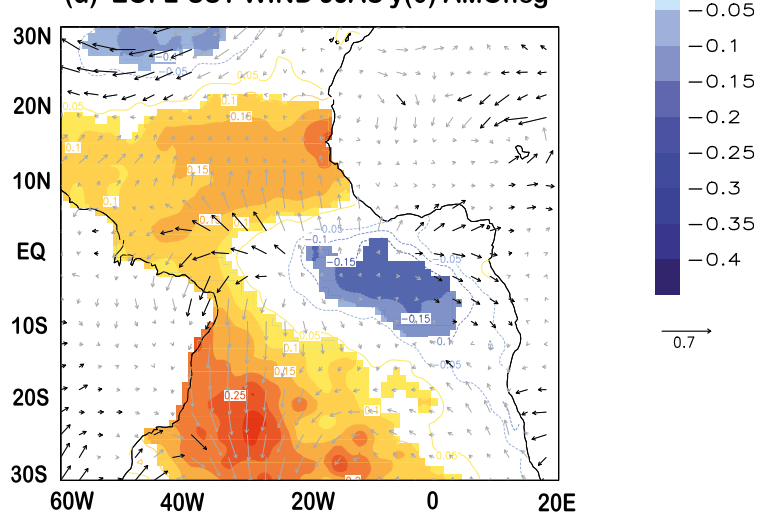

FIG. 9. Regression maps of the seasonal SST and surface wind anomalies over the HS pattern from DJFM (year -1 ) to JJAS (year 0) during negative AMO phases. The total regression fields for the tropical surface wind and SST are presented in gray vectors and contours respectively. Significant values exceeding $95 \%$ confidence level according to a $t$ test are shown in shaded and black vectors.

seems to be favored under negative AMO phases (Fig. 3e). This finding suggests that an additional atmospheric forcing could be operating during those decades. Figure 10 discloses that a winter ENSO appears previous to the HS development. Such positive ENSO seems to excite a Pacific-North American (PNA) pattern, weakening the Azores high in boreal winter (Fig. 10a). Consequently, the trades are reduced in the NTA, warming the northern branch of the HS through latent heat fluxes (Carton et al. 1996; Wagner 1996; Chang et al. 1997). Also, a Pacific-South American (PSA) pattern also emanates from the western tropical Pacific (Handoh et al. 2006b), reaching the Atlantic basin and altering the St. Helena high (Figs. 10a,b). In addition to the extratropical forcings, the interbasin SLP gradient could alter the Walker circulation (Wang 2006), intensifying the equatorial Atlantic easterly winds (Figs. 10a,b). According to these findings, ENSO could act as a precursor of the HS mode. To verify this, we have extracted the ENSO signal from the anomalous
SST field before computing the TAV modes, following different methods based on regression analysis. The removed ENSO-associated SST field has been reconstructed by 1) the first tropical EOF for the 12 seasons, 2) the first tropical EOF only for boreal winter DJFM, and 3) the regression of the DJFM EOF over the following 12 seasons. The TAV modes have been recomputed after subtracting the ENSO signal. The results are very similar in all cases: although the HS signal persists in negative AMO periods, it is the third variability mode and explains significantly less variance (not shown). Eliminating the ENSO signal completely is very difficult, since the impacts are complex and worldwide and occur at a large range of different time scales. Despite this limitation, the HS is found to be at least in part, ENSO-driven in the negative AMO phase. During positive AMO phases, HS-like structures have also been found, but they are less significant and explain only a small amount of variance (not shown). This could be due to the interdecadal changes in ENSO characteristics and 
(a) EOF2-SLP WIND JFMA y(0) AMOneg

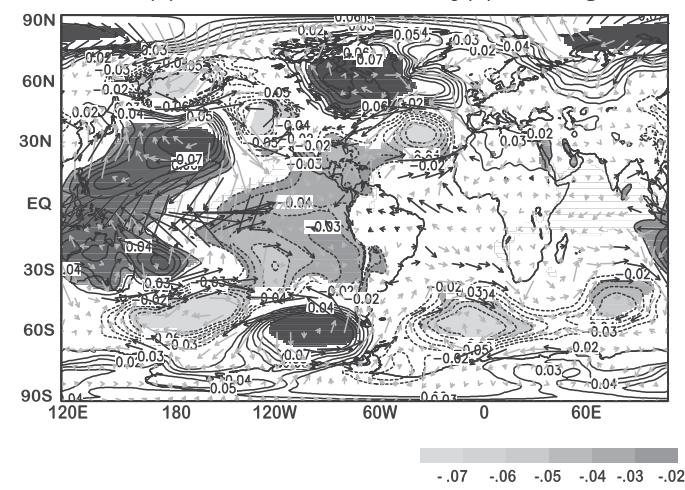

(c) EOF2-SST JFMA y(0) AMOneg

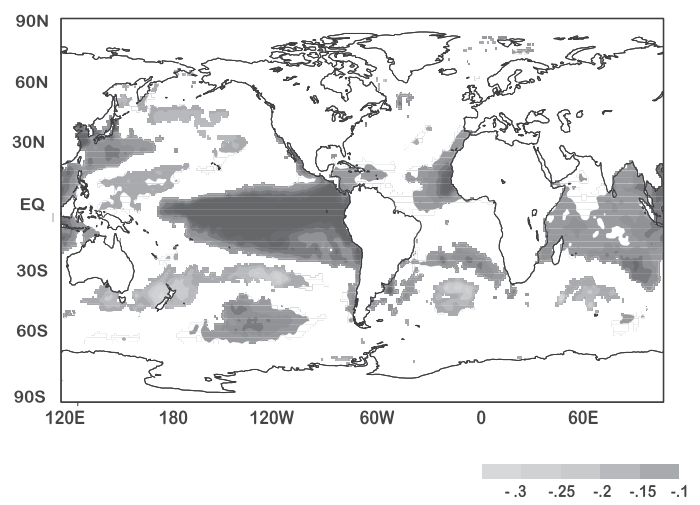

(b) EOF2-SLP WIND MAMJ y(0) AMOneg

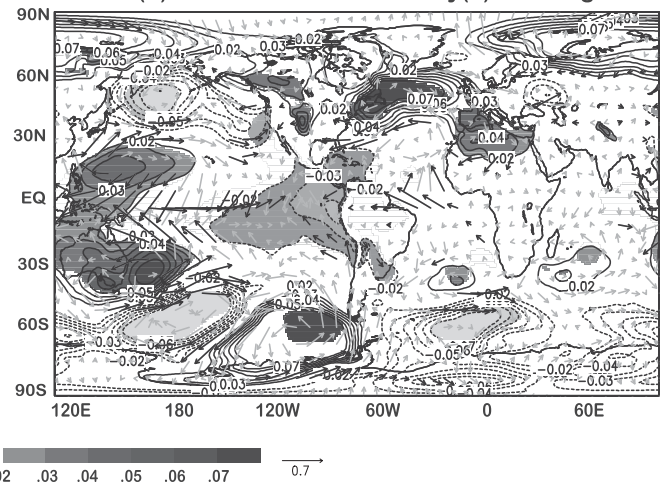

(d) EOF2-SST MAMJ y(0) AMOneg

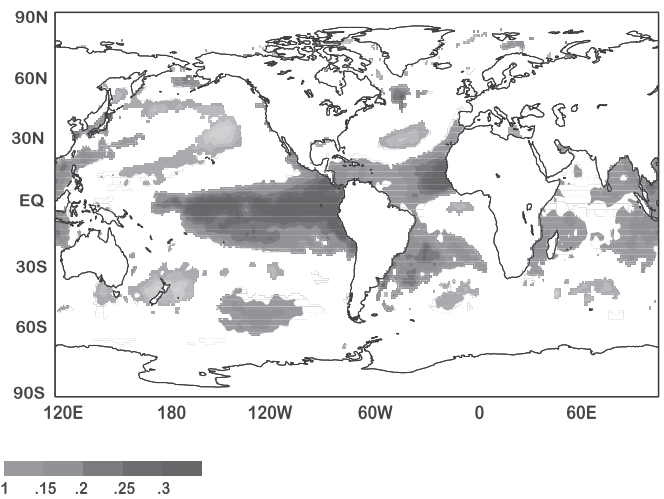

FIG. 10. (a)-(d) Regression maps of the HS pattern over the (top) SLP and surface wind and (bottom) global SST in JFMA and MAMJ for negative AMO phases. Significant values at 95\% confidence level according to a $t$ test are shown in shaded and black vectors. Total regression SLP and wind field are also presented in contours and gray vectors.

teleconnections, as well as the preconditioned TA mean state. Thus, further additional research about the ENSO influence on the HS mode is required and will be carried out in a future work.

\section{3) Multidecadal control of the HS mode}

Although the HS pattern seems to exist along the entire observational record (Fig. 3c), it becomes a dominant mode only during negative AMO decades (Fig. 3e). To confirm this, the TAV modes have been calculated in different AMO subperiods according to negative (1900-25 and 1965-95) and positive (1926-64 and 1996-2013) AMO phases. The results show that HS-like structures can also appear during positive AMO periods (not shown). These HS patterns are associated with weaker (and even not significant) SST anomalies and explain a low fraction of the total variance. This result corroborates our hypothesis: during negative AMO phases, the atmospheric and oceanic conditions seem to be favorable for the emergence of the HS mode.
Previous studies have reported that changes in the global ocean background state can be related to interdecadal variations in ENSO teleconnections (LópezParages and Rodríguez-Fonseca 2012; López-Parages et al. 2016). The Atlantic preconditioned state and its atmospheric response to the ENSO forcing could be also crucial to carry out an interbasin connection (Chang et al. 2006; Lübbecke and McPhaden 2012).

Model results have put forward that Niño-3 SST variability is increased during negative AMO periods (Dong et al. 2006; Dong and Sutton 2007). In our study, no significant changes are found in the observed Niño-3 variance, in negative respect to positive AMO periods (not shown). Nevertheless, the reduced westerly winds in the upper levels could enhance the extratropical ENSO teleconnections (Fig. 2a) (López-Parages and Rodríguez-Fonseca 2012; López-Parages et al. 2016). In addition, the altered Walker circulation with ascending motions over the Pacific and subsidence in the equatorial Atlantic (Fig. 2b), also supports the idea of an interbasin link (Wang 2006) in negative AMO phases. 
We have demonstrated that, under negative AMO phases, the tropical Atlantic mean state has a shallower thermocline in the eastern equatorial Atlantic that contrasts with deeper conditions in the western TA, the key regions for the HS structure (Fig. 2f). This change in the equatorial thermocline slope could cause a more effective Bjerknes feedback, increasing the SST variability (Fig. 1b). Under these changes in the mean TA and enhanced ENSO teleconnections, the emergence of a dominant HS mode under negative AMO phases becomes reasonable.

\section{Summary and conclusions}

In the present study, we have extensively analyzed the tropical Atlantic variability (TAV) over the observational period 1870-2014, focusing on the changes related to different Atlantic multidecadal oscillation (AMO) phases. The results have been put in context of the existing literature about the TAV. The main findings are summarized in Fig. 11 and Table 1 and the conclusions are presented as follows:

- The oceanic and atmospheric mean state is substantially different in negative and positive AMO phases. Negative AMO periods show colder SST over the North Atlantic, an intensified Azores high pressure system, and stronger northern trades. The Walker circulation is enhanced, with ascending motions over the Pacific and subsidence over the Atlantic. Also, the eastern equatorial Atlantic mean thermocline is shallower.

- Observed tropical Atlantic interannual SST variability is modulated by the AMO. During negative AMO phases, the equatorial Atlantic variability is enhanced $(\sim 150 \%)$ during boreal summer and autumn.

- Three interannual modes drive the boreal summer TAV along the twentieth century: the Atlantic Niño, the north tropical Atlantic (NTA), and the so-called horseshoe (HS) pattern. Nevertheless, the emergence and spatial configuration of these modes vary depending on the AMO phase.

- During negative AMO periods, the Atlantic Niño presents larger amplitude and a westward extension of its warm tongue. Its development is associated with the weakening of both the Azores and St. Helena highs, reducing the tropical trades. In contrast, during positive AMO phases, the Atlantic Niño appears related to a dipolar SST pattern in boreal spring, resembling the negative phase of the meridional mode. Under positive AMO, a strengthening of Azores high and lower SLP conditions over STA intensify the northern trades and cause southeastward crossequatorial winds. This meridional pattern evolves into a zonal SLP gradient, reinforcing the westerlies along the equatorial Atlantic.

- The amplitude of the Atlantic Niño during negative AMO increases up to $120 \%$ with respect to positive AMO. This is related to a shallower mean equatorial thermocline during negative AMO that would increase the effect of the Bjerknes feedback and thus the SST variability over the eastern equatorial Atlantic.

- The NTA mode, in its positive phase, displays a warming over the northern tropics associated with a weakening of the Azores high. For negative AMO phases the TNA pattern is shifted northward, with less contribution from the anomalous NW African upwelling system. Different SLP patterns precede the NTA mode depending on the AMO phase: a Scandinavian blocking SLP pattern during negative AMO, and a NAO-like pattern during for positive AMO. In fact, during positive AMO, the NTA conforms the southern branch of the SST tripole forced by a welldeveloped boreal winter-spring NAO.

- The HS mode, in its positive phase, displays a horseshoe shape of warmer SST anomalies in the NTA and STA areas, surrounding an anomalous cooling in the eastern equatorial Atlantic. It appears to be forced by the El Niño phenomenon from the previous winter, through the excitation of extratropical Rossby waves that perturb the subtropical high pressure systems. The positive HS structure seems to be a response to the weakening of both subtropical highs in winter, whereas the eastern equatorial cooling part is partly explained by an acceleration of the crossequatorial southern trade winds. Although the HS mode also occurs during positive AMO, it explains less than $10 \%$ of the variance. An enhancement of ENSO tropical-extratropical teleconnections, together with a more receptive TA mean state, could set up the more favorable conditions for the emergence of the HS mode during negative AMO periods.

Our results show that, along the observational record, the characteristics of the interannual TAV differ depending on the AMO phases (Fig. 11 and Table 1). Changes in the background state, as well as the remote forcing, are responsible for these variations. In this context, diverse oceanic processes could be activated during the development of these modes depending on AMO periods. In this sense, the dominant mechanisms underlying the growth of the Atlantic Niño pattern are currently under debate. In addition to the dynamical processes commonly associated with the Bjerknes feedback (Keenlyside and Latif 2007), other mechanisms have been recently revisited: oceanic Rossby and 
(a) ATLANTIC NIÑO (EOF1) AMO neg

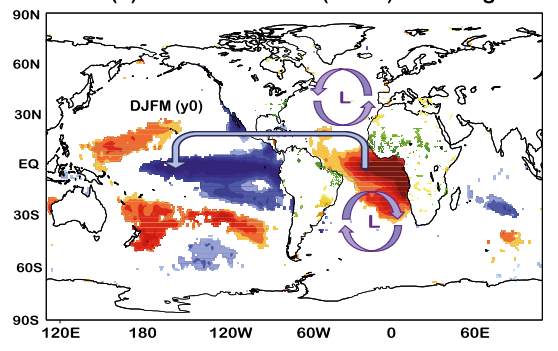

Simutaneous weakening of both
Subtropical lihss during previous
winter and spring

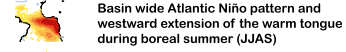

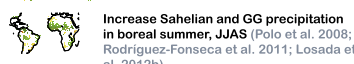

Walker circulation connecting Atlantic
Ninos and Pacific Ninas in next winter
(Rodriguez-Fonseca et al 2009 ; Ding et

(b) NTA (EOF3) AMOneg
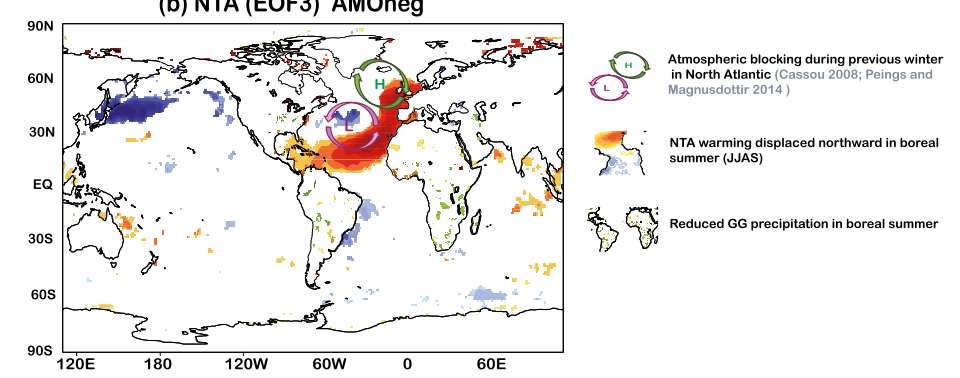

(c) HORSE-SHOE (EOF2) AMO neg
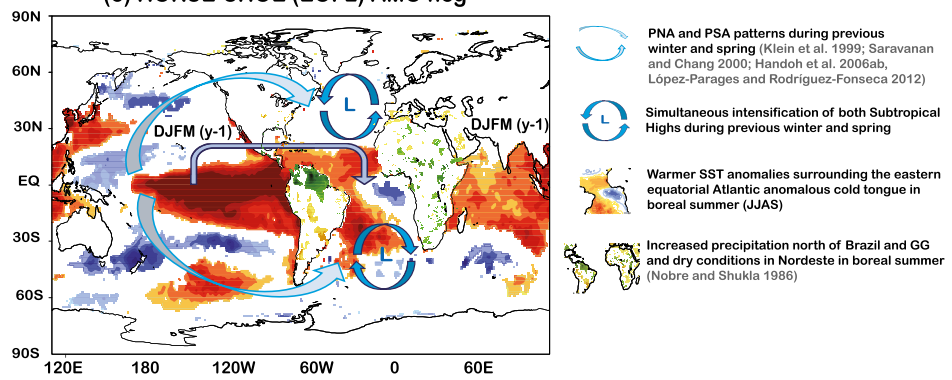

(d) ATLANTIC NIÑO (EOF1) AMOpos

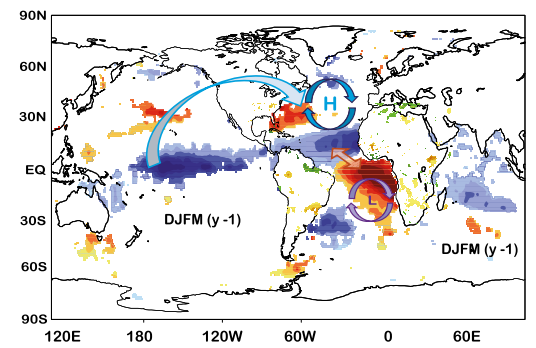

A CP Nina impacts in NTA through PNA pattern,
creating a negative Meridional Mode in boreal
spring.

If Itensified Aaross High and Low pressure in
south TA during previous winter and spring.

Dipole-like Attantic Niño configuration in boreal

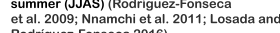
Rodriguez-Fonseca 2016)

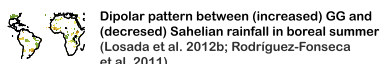

(e) NTA (EOF2) AMOpos

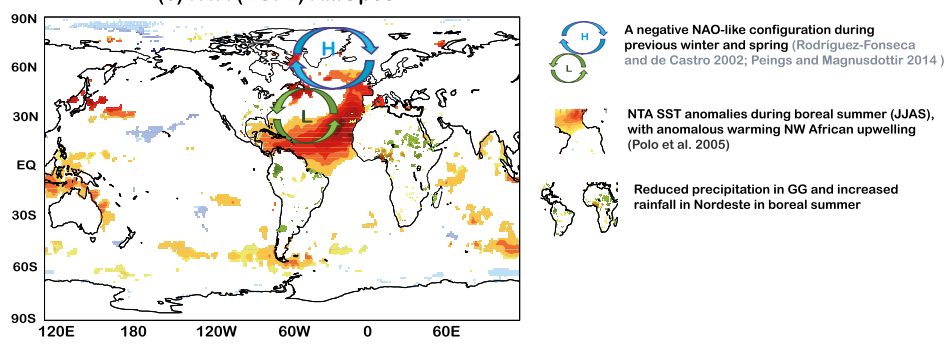

FIG. 11. Scheme of the characteristics of TAV modes in different AMO phases with their forcings and impacts. 
TABLE 1. Summary of main characteristic of the summer modes identified for different AMO phases and its characteristics based on our analysis and related to the existing literature.

\begin{tabular}{|c|c|c|c|}
\hline Modes & AMO positive & AMO negative & Impacts \\
\hline \multirow[t]{6}{*}{ Atlantic Niño mode } & $36.44 \%$ variance & $37.03 \%$ variance & Positive AMO \\
\hline & $\begin{array}{l}\text { Meridional seesaw SLP } \\
\text { pattern }\end{array}$ & $\begin{array}{l}\text { Weakening/strengthening of both } \\
\text { subtro pical highs }\end{array}$ & $\begin{array}{l}\text { Increased rainfall in the Gulf of Guinea } \\
\text { (GG) and dry conditions in Sahel } \\
\text { (Rodríguez-Fonseca et al. 2011; } \\
\text { Nnamchi and Li 2011; Losada et al. } \\
\text { 2012a) }\end{array}$ \\
\hline & \multirow{4}{*}{$\begin{array}{l}\text { Preceded by a boreal spring } \\
\text { meridional mode-like } \\
\text { configuration (Chang } \\
\text { et al. 1997; Chiang and } \\
\text { Vimont 2004) } \\
\text { Dipolar SST structure } \\
\text { between eastern equato- } \\
\text { rial Atlantic and WSTA } \\
\text { (Nnamchi et al. 2011; } \\
\text { Losada and Rodríguez- } \\
\text { Fonseca 2016) } \\
\text { Possible WES feedback } \\
\text { (Amaya et al. 2017) in } \\
\text { boreal spring and heat } \\
\text { flux contribution in sum- } \\
\text { mer (Nnamchi et al. } \\
\text { 2016) }\end{array}$} & $\begin{array}{l}\text { Preceded by a boreal spring Benguela } \\
\text { Niño-like (Florenchie et al. 2003; } \\
\text { Lübbecke et al. 2010) basinwide } \\
\text { pattern }\end{array}$ & $\begin{array}{l}\text { Not related to ENSO } \\
\text { (Rodríguez-Fonseca et al. 2009; } \\
\quad \text { Martín-Rey et al. 2014; Losada and } \\
\text { Rodríguez-Fonseca 2016) }\end{array}$ \\
\hline & & \multirow{3}{*}{$\begin{array}{l}\text { Stronger SST anomalies and a } \\
\text { westward extension of the warm } \\
\text { tongue (Polo et al. 2008; } \\
\text { Rodríguez-Fonseca et al. 2009; } \\
\text { Martín-Rey et al. 2014; Losada } \\
\text { and Rodríguez-Fonseca 2016) } \\
\text { Possible Bjerknes feedback (Zebiak } \\
\text { 1993; Keenlyside and Latif 2007; } \\
\text { Lübbecke and McPhaden 2013) }\end{array}$} & Negative AMO \\
\hline & & & $\begin{array}{l}\text { Increased rainfall in GG and Sahel } \\
\text { (Polo et al. 2008; Rodríguez- } \\
\text { Fonseca et al. 2011; Losada et al. } \\
\text { 2012a) } \\
\text { Impact on next winter ENSO }\end{array}$ \\
\hline & & & $\begin{array}{l}\text { (Rodríguez-Fonseca et al. 2009; Ding } \\
\text { et al. 2012; Polo et al. 2015a; } \\
\text { Losada and Rodríguez-Fonseca } \\
\text { 2016) }\end{array}$ \\
\hline \multirow[t]{4}{*}{ NTA mode } & $23.92 \%$ variance & $14.11 \%$ variance & $\begin{array}{l}\text { Upwelling coastal variations (Polo } \\
\text { et al. 2005) }\end{array}$ \\
\hline & \multirow{3}{*}{$\begin{array}{l}\text { Associated with NAO } \\
\text { SST anomalies isolated in } \\
\text { NTA region. } \\
\text { Possible wind-induced } \\
\text { latent heat fluxes (Chang } \\
\text { et al. 1997; Amaya et al. } \\
\text { 2017) }\end{array}$} & Associated with a & \multirow{3}{*}{$\begin{array}{l}\text { Increase winter precipitation in } \\
\text { Iberian Peninsula (Rodriguez- } \\
\text { Fonseca and de Castro 2002) and } \\
\text { decreased rainfall in GG. }\end{array}$} \\
\hline & & North Atmospheric blocking. & \\
\hline & & $\begin{array}{l}\text { SST anomalies displaced northward } \\
\text { in NTA region } \\
\text { Possible wind-induced latent heat } \\
\text { fluxes (Chang et al. 1997; Amaya } \\
\text { et al. 2017) }\end{array}$ & \\
\hline HS-like mode & - & $\begin{array}{l}18.86 \% \text { variance } \\
\text { Forced by ENSO during previous } \\
\text { winter } \\
\text { Preceded by spring SST anomalies } \\
\text { in NTA and STA. Similar to } \\
\text { pan-Atlantic decadal oscillation } \\
\text { pattern (Xie and Tanimoto } \\
\text { 1998) } \\
\text { Possible wind-induced latent heat } \\
\text { fluxes (Amaya et al. 2017; Nnamchi } \\
\text { et al. 2016) and Bjerknes feedback } \\
\text { (Keenlyside and Latif 2007). }\end{array}$ & $\begin{array}{l}\text { Increased precipitation north of } \\
\text { Brazil and GG, while dry condi- } \\
\text { tions in Nordeste Brazil (Nobre } \\
\text { and Shukla 1996) }\end{array}$ \\
\hline
\end{tabular}

Kelvin waves (Foltz and McPhaden 2010; Lübbecke et al. 2010; Lübbecke and McPhaden 2012; Lübbecke et al. 2014), meridional equatorward advection of NTA SST anomalies (Richter et al. 2013), or air-sea thermodynamic feedbacks (Nnamchi et al. 2016). Regarding the new overlooked HS pattern, a detailed description of the air-sea interactions responsible for its development is required.
Acknowledgments. The research leading to these results received funding from the EU FP7/2007-2013 under Grant Agreement 603521 (PREFACE project). This study was also supported by the Spanish MINNECO project CGL2012-38923-C02-01. TL is currently supported by a Juan de la Cierva research contract of MINNECO (Spain). We thank Julian Villamayor and Elsa Mohino for their help in the computation of the decadal variability AMO 
pattern. We also want to thank Ben Parkes for his help in improving the writing of the manuscript.

\section{REFERENCES}

Amaya, D. J., M. J. DeFlorio, A. J. Miller, and S.-P. Xie, 2017: WES feedback and the Atlantic meridional mode: Observations and CMIP5 comparisons. Climate Dyn., 49, 1655-1679, https://doi.org/10.1007/s00382-016-3411-1.

Andreoli, R. V., and M. T. Kayano, 2003: Evolution of the equatorial and dipole modes of the sea-surface temperature in the tropical Atlantic at decadal scale. Meteor. Atmos. Phys., 83, 277-285, https://doi.org/10.1007/s00703-002-0568-4.

Bjerknes, J., 1969: Atmospheric teleconnections from the equatorial Pacific. Mon. Wea. Rev., 97, 163-172, https://doi.org/ 10.1175/1520-0493(1969)097<0163:ATFTEP $>2.3 . C O ; 2$.

Butterworth, S., 1930: On the theory of filter amplifiers. Exp. Wireless Wireless Eng., 7, 536-541, http://www.gonascent.com/ papers/butter.pdf.

Carton, J. A., and B. Huang, 1994: Warm events in the tropical Atlantic. J. Phys. Oceanogr., 24, 888-903, https://doi.org/ 10.1175/1520-0485(1994)024<0888:WEITTA > 2.0.CO;2.

$\longrightarrow$ X. Cao, B. S. Giese, and A. M. Da Silva, 1996: Decadal and interannual SST variability in the tropical Atlantic Ocean. J. Phys. Oceanogr., 26, 1165-1175, https://doi.org/10.1175/ 1520-0485(1996)026<1165:DAISVI >2.0.CO;2.

Cassou, C., 2008: Intraseasonal interaction between the MaddenJulian oscillation and the North Atlantic Oscillation. Nature, 455, 523-527, https://doi.org/10.1038/nature07286.

Chang, P., L. Ji, and H. Li, 1997: A decadal climate variation in the tropical Atlantic Ocean from thermodynamic air-sea interactions. Nature, 385, 516-518, https://doi.org/10.1038/385516a0.

__ , Y. Fang, R. Saravanan, L. Ji, and H. Seidel, 2006: The cause of the fragile relationship between the Pacific El Niño and the Atlantic Niño. Nature, 443, 324-328, https://doi.org/ 10.1038/nature05053.

Chiang, J. C. H., and D. J. Vimont, 2004: Analogous Pacific and Atlantic meridional modes of tropical atmosphere-ocean variability. J. Climate, 17, 4143-4158, https://doi.org/10.1175/ JCLI4953.1.

, Y. Kushnir, and S. E. Zebiak, 2000: Interdecadal changes in eastern Pacific ITCZ variability and its influence on the Atlantic ITCZ. Geophys. Res. Lett., 27, 3687-3690, https://doi.org/ 10.1029/1999GL011268.

- - - and A. Giannini, 2002: Deconstructing Atlantic intertropical convergence zone variability: Influence of the local cross-equatorial sea surface temperature gradient and remote forcing from the eastern equatorial Pacific. J. Geophys. Res., 107, 4004, https://doi.org/10.1029/2000JD000307.

Czaja, A., P. van der Vaart, and J. Marshall, 2002: A diagnostic study of the role of remote forcing in tropical Atlantic variability. J. Climate, 15, 3280-3290, https://doi.org/10.1175/ 1520-0442(2002)015<3280:ADSOTR>2.0.CO;2.

Davini, P., J. von Hardenberg, and S. Corti, 2015: Tropical origin for the impacts of the Atlantic multidecadal variability on the Euro-Atlantic climate. Environ. Res. Lett., 10, 094010, https:// doi.org/10.1088/1748-9326/10/9/094010.

Ding, H., N. S. Keenlyside, and M. Latif, 2012: Impact of the equatorial Atlantic on the El Niño Southern Oscillation. Climate Dyn., 38, 1965-1972, https://doi.org/10.1007/s00382-011-1097-y.

Dong, B., and R. T. Sutton, 2007: Enhancement of ENSO variability by a weakened Atlantic thermohaline circulation in a coupled GCM. J. Climate, 20, 4920-4939, https://doi.org/ 10.1175/JCLI4284.1.

,$--\ldots$, and A. A. Scaife, 2006: Multidecadal modulation of El Niño-Southern Oscillation (ENSO) variance by Atlantic Ocean sea surface temperatures. Geophys. Res. Lett., 33, L08705, https://doi.org/10.1029/2006GL025766.

Enfield, D. B., and D. A. Mayer, 1997: Tropical Atlantic sea surface temperature variability and its relation to El Niño-Southern Oscillation. J. Geophys. Res., 102, 929-945, https://doi.org/ 10.1029/96JC03296.

Florenchie, P., J. R. E. Lutjeharms, C. J. C. Reason, S. Masson, and M. Rouault, 2003: The source of Benguela Niños in the South Atlantic Ocean. Geophys. Res. Lett., 30, 1505, https://doi.org/ 10.1029/2003GL017172.

Foltz, G. R., and M. J. McPhaden, 2010: Interaction between the Atlantic meridional and Niño modes. Geophys. Res. Lett., 37, L18604, https://doi.org/10.1029/2010GL044001.

Giese, B. S., and S. Ray, 2011: El Niño variability in simple ocean data assimilation (SODA), 1871-2008. J. Geophys. Res., 116, C02024, https://doi.org/10.1029/2010JC006695.

Goldenberg, S. B., C. W. Landsea, A. M. Mestas-Nuñez, and W. M. Gray, 2001: The recent increase in Atlantic hurricane activity: Causes and implications. Science, 293, 474-479, https://doi.org/ 10.1126/science. 1060040.

Haarsma, R. J., E. Campos, W. Hazeleger, and C. Severijns, 2008: Influence of the meridional overturning circulation on tropical Atlantic climate and variability. J. Climate, 21, 1403-1416, https://doi.org/10.1175/2007JCLI1930.1.

Ham, Y.-G., J.-S. Kug, J.-Y. Park, and F.-F. Jin, 2013: Sea surface temperature in the north tropical Atlantic as a trigger for El Niño/Southern Oscillation events. Nat. Geosci., 6, 112-116, https://doi.org/10.1038/ngeo1686.

Handoh, I. C., A. J. Matthews, G. R. Bigg, and D. P. Stevens, 2006a: Interannual variability of the tropical Atlantic independent of and associated with ENSO: Part I. The north tropical Atlantic. Int. J. Climatol., 26, 1937-1956, https://doi.org/ 10.1002/joc. 1343 .

, G. R. Bigg, A. J. Matthews, and D. P. Stevens, 2006b: Interannual variability of the tropical Atlantic independent of and associated with ENSO: Part II. The south tropical Atlantic. Int. J. Climatol., 26, 1957-1976, https://doi.org/ 10.1002/joc.1342.

Harris, I., P. D. Jones, T. J. Osborn, and D. H. Lister, 2014: Updated high-resolution grids of monthly climatic observationsThe CRU TS3.10 dataset. Int. J. Climatol., 34, 623-642, https:// doi.org/10.1002/joc.3711.

Horel, J. D., and J. M. Wallace, 1981: Planetary-scale atmospheric phenomena associated with the Southern Oscillation Mon. Wea. Rev., 109, 813-829, https://doi.org/10.1175/ 1520-0493(1981)109<0813:PSAPAW > 2.0.CO;2.

Huang, B., and Coauthors, 2015: Extended reconstructed sea surface temperature version 4 (ERSST.v4). Part I: Upgrades and intercomparisons. J. Climate, 28, 911-930, https://doi.org/ 10.1175/JCLI-D-14-00006.1.

Hurrell, J. W., Y. Kushnir, and M. Visbeck, 2001: The North Atlantic Oscillation. Science, 291, 603-605, https://doi.org/ 10.1126/science. 1058761.

Kaiser, H. F., 1958: The varimax criterion for analytic rotations in factor analysis. Psychometrika, 23, 187-200, https://doi.org/ 10.1007/BF02289233.

Keenlyside, N. S., and M. Latif, 2007: Understanding equatorial Atlantic interannual variability. J. Climate, 20, 131-142, https://doi.org/10.1175/JCLI3992.1. 
Kerr, R. A., 2000: A North Atlantic climate pacemaker for the centuries. Science, 288, 1984-1985, https://doi.org/10.1126/ science.288.5473.1984.

Knight, J. R., C. K. Folland, and A. A. Scaife, 2006: Climate impacts of the Atlantic multidecadal oscillation. Geophys. Res. Lett., 33, L17706, https://doi.org/10.1029/2006GL026242.

Kossin, J. P., and D. J. Vimont, 2007: A more general framework for understanding Atlantic hurricane variability and trends Bull. Amer. Meteor. Soc., 88, 1767-1781, https://doi.org/ 10.1175/BAMS-88-11-1767.

Kucharski, F., A. Bracco, J. H. Yoo, and F. Molteni, 2008: Atlantic forced component of the Indian monsoon interannual variability. Geophys. Res. Lett., 35, L04706, https://doi.org/ 10.1029/2007GL033037.

Latif, M., and A. Grötzner, 2000: The equatorial Atlantic Oscillation and its response to ENSO. Climate Dyn., 16, 213-218, https://doi.org/10.1007/s003820050014.

Levine, A. F. Z., M. J. McPhaden, and D. M. W. Frierson, 2017: The impact of the AMO on multidecadal ENSO variability. Geophys. Res. Lett., 44, 3877-3886, https://doi.org/10.1002/2017GL072524.

Li, J., C. Sun, and F.-F. Jin, 2013: NAO implicated as a predictor of Northern Hemisphere mean temperature multidecadal variability. Geophys. Res. Lett., 40, 5497-5502, https://doi.org/ 10.1002/2013GL057877.

López-Parages, J., and B. Rodríguez-Fonseca, 2012: Multidecadal modulation of El Niño influence on the Euro-Mediterranean rainfall. Geophys. Res. Lett., 39, L02704, https://doi.org/ 10.1029/2011GL050049.

$\longrightarrow,-$, D. Dommenget, and C. Frauen, 2016: ENSO influence on the North Atlantic European climate: A non-linear and non-stationary approach. Climate Dyn., 47, 2071-2084, https:// doi.org/10.1007/s00382-015-2951-0.

Losada, T., and B. Rodríguez-Fonseca, 2016: Tropical atmospheric response to decadal changes in the Atlantic equatorial mode. Climate Dyn., 47, 1211-1224, https://doi.org/10.1007/s00382 015-2897-2.

,,-- I. Polo, S. Janicot, S. Gervois, F. Chauvin, and P. Ruti, 2010: Tropical response to the Atlantic equatorial mode: AGCM multimodel approach. Climate Dyn., 35, 45-52, https://doi.org/10.1007/s00382-009-0624-6.

,-- E. Mohino, J. Bader, S. Janicot, and C. R. Mechoso, 2012a: Tropical SST and Sahel rainfall: A non-stationary relationship. Geophys. Res. Lett., 39, L12705, https://doi.org/ 10.1029/2012GL052423.

_, _ , and F. Kucharski, 2012b: Tropical influence on the summer Mediterranean climate. Atmos. Sci. Lett., 13, 36-42, https://doi.org/10.1002/asl.359.

Lübbecke, J. F., and M. J. McPhaden, 2012: On the inconsistent relationship between Pacific and Atlantic Niños. J. Climate, 25, 4294-4303, https://doi.org/10.1175/JCLI-D-11-00553.1.

— and - 2013: A comparative stability analysis of Atlantic and Pacific Niño modes. J. Climate, 26, 5965-5980, https://doi.org/ 10.1175/JCLI-D-12-00758.1.

—, C. W. Böning, N. S. Keenlyside, and S.-P. Xie, 2010: On the connection between Benguela and equatorial Atlantic Niños and the role of the South Atlantic anticyclone. J. Geophys. Res., 115, C09015, https://doi.org/10.1029/2009JC005964.

- N. J. Burls, C. J. C. Reason, and M. J. McPhaden, 2014: Variability in the South Atlantic anticyclone and the Atlantic Niño mode. J. Climate, 27, 8135-8150, https://doi.org/10.1175/JCLI-D-14-00202.1.

Mariotti, A., N. Zeng, and K.-M. Lau, 2002: Euro-Mediterranean rainfall and ENSO-A seasonally varying relationship. Geophys. Res. Lett., 29, 1621, https://doi.org/10.1029/2001GL014248.
Martín-Rey, M., B. Rodríguez-Fonseca, I. Polo, and F. Kucharski, 2014: On the Atlantic-Pacific Niños connection: A multidecadal modulated mode. Climate Dyn., 43, 3163-3178, https://doi.org/10.1007/s00382-014-2305-3.

,-- , and 2015: Atlantic opportunities for ENSO prediction. Geophys. Res. Lett., 42, 6802-6810, https://doi.org/ 10.1002/2015GL065062.

Merle, J., 1980: Seasonal variation of heat-storage in the tropical Atlantic Ocean. Oceanol. Acta, 3, 455-463, http://horizon.documentation.ird.fr/ exl-doc/pleins_textes/pleins_textes_5/b_fdi_00/00018.pdf.

Mohino, E., S. Janicot, and J. Bader, 2011: Sahel rainfall and decadal to multi-decadal sea surface temperature variability. Climate Dyn., 37, 419-440, https://doi.org/10.1007/s00382-010-0867-2.

Moura, A. D., and J. Shukla, 1981: On the dynamics of droughts in northeast Brazil: Observations, theory and numerical experiments with a general circulation model. J. Atmos. Sci., 38, 2653-2675, https:// doi.org/10.1175/1520-0469(1981)038<2653:OTDODI >2.0.CO;2.

Münnich, M., and J. D. Neelin, 2005: Seasonal influence of ENSO on the Atlantic ITCZ and equatorial South America. Geophys. Res. Lett., 32, L21709, https://doi.org/10.1029/2005GL023900.

Murtugudde, R. G., J. Ballabrera-Poy, J. Beauchamp, and A. J. Busalacchi, 2001: Relationship between zonal and meridional modes in the tropical Atlantic. Geophys. Res. Lett., 28, 4463 4466, https://doi.org/10.1029/2001GL013407.

Nnamchi, H. C., and J. Li, 2011: Influence of the South Atlantic Ocean dipole on West African summer precipitation. J. Climate, 24, 1184-1197, https://doi.org/10.1175/2010JCLI3668.1. and R. N. C. Anyadike, 2011: Does a dipole mode really exist in the South Atlantic Ocean? J. Geophys. Res., 116, D15104, https://doi.org/10.1029/2010JD015579.

, F. Kucharski, I.-S. Kang, N. S. Keenlyside, P. Chang, and R. Farneti, 2015: Thermodynamic controls of the Atlantic Niño. Nat. Commun., 6, 8895, https://doi.org/10.1038/ncomms9895.

$-,-\longrightarrow,-,-,-$, and,- 2016 : An equatorialextratropical dipole structure of the Atlantic Niño. J. Climate, 29, 7295-7311, https://doi.org/10.1175/JCLI-D-15-0894.1.

Nobre, P., and J. Shukla, 1996: Variations in sea surface temperature, wind stress, and rainfall over the tropical Atlantic and South America. J. Climate, 9, 2464-2479, https://doi.org/ 10.1175/1520-0442(1996)009<2464:VOSSTW >2.0.CO;2.

North, G. R., T. L. Bell, F. Cahalan, and F. J. Moeng, 1982: Sampling errors in the estimation of empirical orthogonal functions. Mon. Wea. Rev., 110, 699-706, https://doi.org/10.1175/ 1520-0493(1982)110<0699:SEITEO > 2.0.CO;2.

Oettli, P., Y. Morioka, and T. Yamagata, 2016: A regional climate mode discovered in the North Atlantic: Dakar Niño/Niña. Sci. Rep., 6, 18782, https://doi.org/10.1038/srep18782.

Pan, L.-L., 2005: Observed positive feedback between the NAO and the North Atlantic SSTA tripole. Geophys. Res. Lett., 32, L06707, https://doi.org/10.1029/2005GL022427.

Peings, Y., and G. Magnusdottir, 2014: Forcing of the wintertime atmospheric circulation by the multidecadal fluctuations of the North Atlantic Ocean. Environ. Res. Lett., 9, 034018, https:// doi.org/10.1088/1748-9326/9/3/034018.

Poli, P., and Coauthors, 2013: The data assimilation system and initial performance evaluation of the ECMWF pilot reanalysis of the 20th-century assimilating surface observations only (ERA-20C). ERA Rep. Series 14, ECMWF, 62 pp., http:// www.ecmwf.int/en/elibrary/11699-data-assimilation-system-andinitial-performance-evaluation-ecmwf-pilot-reanalysis.

Polo, I., B. Rodríguez-Fonseca, and J. Sheinbaum, 2005: Northwest Africa upwelling and the Atlantic climate variability. Geophys. Res. Lett., 32, L23702, https://doi.org/10.1029/2005GL023883. 
— — - T. Losada, and J. García-Serrano, 2008: Tropical Atlantic variability modes (1979-2002). Part I: Time-evolving SST modes related to West African rainfall. J. Climate, 21, 6457-6475, https://doi.org/10.1175/2008JCLI2607.1.

— B. W. Dong, and R. T. Sutton, 2013: Changes in tropical Atlantic interannual variability from a substantial weakening of the meridional overturning circulation. Climate Dyn., 41, 2765-2784, https://doi.org/10.1007/s00382-013-1716-x.

— M. Martin-Rey, B. Rodríguez-Fonseca, F. Kucharski, and C. R. Mechoso, 2015a: Processes in the Pacific La Niña onset triggered by the Atlantic Niño. Climate Dyn., 44, 115-131, https://doi.org/10.1007/s00382-014-2354-7.

— A. Lazar, B. Rodríguez-Fonseca, and J. Mignot, 2015b: Growth and decay of the equatorial Atlantic SST mode by means of closed heat budget in a coupled general circulation model. Front. Earth Sci., 3, 37, https://doi.org/10.3389/feart.2015.00037.

Pozo-Vázquez, D., M. J. Esteban-Parra, F. S. Rodrigo, and Y. CastroDíez, 2001: A study of NAO variability and its possible nonlinear influences on European surface temperature. Climate Dyn., 17, 701-715, https://doi.org/10.1007/s003820000137.

Rajagopalan, B., Y. Kushnir, and Y. M. Tourre, 1998: Observed decadal midlatitude and tropical Atlantic climate variability. Geophys. Res. Lett., 25, 3967-3970, https://doi.org/10.1029/ 1998GL900065.

Rayner, N. A., D. E. Parker, E. B. Horton, C. K. Folland, L. V. Alexander, D. P. Rowell, E. C. Kent, and A. Kaplan, 2003: Global analyses of sea surface temperature, sea ice, and night marine air temperature since the late nineteenth century. J. Geophys. Res,. 108, 4407, https://doi.org/10.1029/2002JD002670.

Richman, M. B., 1986: Rotation of principal components. J. Climatol., 6, 293-335, https://doi.org/10.1002/joc.3370060305.

Richter, I., S. K. Behera, Y. Masumoto, B. Taguchi, N. Komori, and T. Yamagata, 2010: On the triggering of Benguela Niños: Remote equatorial versus local influences. Geophys. Res. Lett., 37, L20604, https://doi.org/10.1029/2010GL044461.

,,,,---- H. Sasaki, and T. Yamagata, 2013: Multiple causes of interannual sea surface temperature variability in the equatorial Atlantic Ocean. Nat. Geosci., 6, 43-47, https:// doi.org/10.1038/ngeo1660.

Rodríguez-Fonseca, B., and M. de Castro, 2002: On the connection between winter anomalous precipitation in the Iberian Peninsula and North West Africa and the summer subtropical Atlantic sea surface temperature. Geophys. Res. Lett., 29, 1863, https://doi.org/10.1029/2001GL014421.

—, I. Polo, J. García-Serrano, T. Losada, E. Mohino, C. R. Mechoso, and F. Kucharski, 2009: Are Atlantic Niños enhancing Pacific ENSO events in recent decades? Geophys. Res. Lett., 36, L20705, https://doi.org/10.1029/2009GL040048. , and Coauthors, 2011: Interannual and decadal SST-forced responses of the West African monsoon. Atmos. Sci. Lett., 12, 67-74, https://doi.org/10.1002/asl.308.

Ruiz-Barradas, A., J. A. Carton, and S. Nigam, 2000: Structure of interannual-to-decadal climate variability in the tropical Atlantic sector. J. Climate, 13, 3285-3297, https://doi.org/10.1175/ 1520-0442(2000)013<3285:SOITDC $>2.0$.CO;2.

Saravanan, R., and P. Chang, 2000: Interaction between tropical Atlantic variability and El Niño-Southern Oscillation. J. Climate, 13, 2177-2194, https://doi.org/10.1175/1520-0442(2000)013<2177: IBTAVA $>2.0 . C O ; 2$.

Servain, J., I. Wainer, J. P. McCreary Jr., and A. Dessier, 1999: Relationship between the equatorial and meridional modes of climatic variability in the tropical Atlantic. Geophys. Res. Lett., 26, 485-488, https://doi.org/10.1029/1999GL900014.

Shannon, L. V., A. J. Boyd, G. B. Brundrit, and J. Taunton-Clark, 1986: On the existence of an El Niño-type phenomenon in the Benguela system. J. Mar. Res., 44, 495-520, https://doi.org/ 10.1357/002224086788403105.

Sutton, R. T., and D. L. R. Hodson, 2003: Influence of the ocean on North Atlantic climate variability 1871-1999. J. Climate, 16, 3296-3313, https://doi.org/10.1175/1520-0442(2003)016<3296: IOTOON $>2.0 . \mathrm{CO} ; 2$.

—, and B. Dong, 2012: Atlantic Ocean influence on a shift in European climate in the 1990s. Nat. Geosci., 5, 788-792, https://doi.org/10.1038/ngeo1595.

Svendsen, L., N. G. Kvamst $\varnothing$, and N. S. Keenlyside, 2014: Weakening AMOC connects equatorial Atlantic and Pacific interannual variability. Climate Dyn., 43, 2931-2941, https://doi.org/ 10.1007/s00382-013-1904-8.

Tokinaga, H., and S.-P. Xie, 2011: Weakening of the equatorial Atlantic cold tongue over the past six decades. Nat. Geosci., 4 , 222-226, https://doi.org/10.1038/ngeo1078.

Villamayor, J., and E. Mohino, 2015: Robust Sahel drought due to the Interdecadal Pacific Oscillation in CMIP5 simulations. Geophys. Res. Lett., 42, 1214-1222, https://doi.org/10.1002/ 2014 GL062473.

Vimont, D. J., and J. P. Kossin, 2007: The Atlantic meridional mode and hurricane activity. Geophys. Res. Lett., 34, L07709, https://doi.org/10.1029/2007GL029683.

von Storch, H., and F. W. Zwiers, 2001: Statistical Analysis in Climate Research. Cambridge University Press, 484 pp.

Wagner, R. G., 1996: Mechanisms controlling variability of the interhemispheric sea surface temperature gradient in the tropical Atlantic. J. Climate, 9, 2010-2019, https://doi.org/ 10.1175/1520-0442(1996)009<2010:MCVOTI > 2.0.CO;2.

Wang, C., 2006: An overlooked feature of tropical climate: InterPacific-Atlantic variability. Geophys. Res. Lett., 33, L12702, https://doi.org/10.1029/2006GL026324.

Wang, L., J.-Y. Yu, and H. Paek, 2017: Enhanced biennial variability in the Pacific due to Atlantic capacitor effect. Nat. Commun., 8, 14887, https://doi.org/10.1038/ncomms14887.

Xie, L., T. Yan, and L. Pietrafesa, 2005: The effect of Atlantic sea surface temperature dipole mode on hurricanes: Implications for the 2004 Atlantic hurricane season. Geophys. Res. Lett., 32 , L03701, https://doi.org/10.1029/2004GL021702.

Xie, S.-P., and G. H. Philander, 1994: A coupled oceanatmosphere model of relevance to the ITCZ in the eastern Pacific. Tellus, 46A, 340-350, https://doi.org/10.3402/ tellusa.v46i4.15484.

_ cillation. Geophys. Res. Lett., 25, 2185-2188, https://doi.org/ 10.1029/98GL01525.

Zebiak, S. E., 1993: Air-sea interaction in the equatorial Atlantic region. J. Climate, 6, 1567-1586, https://doi.org/10.1175/ 1520-0442(1993)006<1567:AIITEA > 2.0.CO;2.

Zhang, R. H., and T. L. Delworth, 2007: Impact of the Atlantic multidecadal oscillation on North Pacific climate variability. Geophys. Res. Lett., 34, L23708, https://doi.org/10.1029/2007GL031601.

Zhu, J., B. Huang, and Z. Wu, 2012: The role of ocean dynamics in the interaction between the Atlantic meridional and equatorial modes. J. Climate, 25, 3583-3598, https://doi.org/10.1175/ JCLI-D-11-00364.1. 